\title{
The role of the openings in the out-of-plane behaviour of masonry infill walls
}

\author{
André Furtado $^{a}$, António Arêde ${ }^{\mathrm{a}}$, Hugo Rodrigues ${ }^{\mathrm{b}, *}$, Humberto Varum ${ }^{\mathrm{a}}$ \\ a CONSTRUCT-LESE, Department of Civil Engineering, Faculty of Engineering of the University of Porto, Portugal \\ ${ }^{\mathrm{b}}$ RISCO, Department of Civil Engineering, University of Aveiro, Portugal
}

\section{A R T I C L E I N F O}

\section{Keywords:}

Masonry infill walls

Openings

Out-of-plane behaviour

Experimental testings

Maximum strength

Energy dissipation

\begin{abstract}
A B S T R A C T
This research work aims to present an experimental study concerning the effect of the openings in the out-ofplane (OOP) behaviour of masonry infills in RC buildings. The experimental campaign comprises the OOP testing of three full-scale infill walls made up of horizontal hollow clay bricks, two of them with a central window and the remaining one with a central door. One of the specimens with a central opening was first subjected to a previous in-plane test and, after that, the damaged wall was subjected to an OOP test. All the tests consisted of applying a loading-unloading-reloading history of imposed displacements in the OOP direction through a uniformly distributed load. An innovative setup was used and adapted for each wall typology. The results are presented in terms of OOP force-displacement responses, damage evolution, relative stiffness and energy dissipation capacity. Finally, the test results are compared to each other to assess the effect of: i) the area of the opening; and ii) the previous damage. It was found that the openings reduced the maximum strength of $30 \%$ for undamaged panels, and it occurred for lower displacement demands. The increase of the opening area did not affect the peak load; however, it reduced their energy dissipation capacity significantly. The energy dissipation capacity reduced from $42 \%$ to $70 \%$.
\end{abstract}

\section{Introduction}

The masonry infill walls (MIW) are widely spread over the reinforced concrete (RC) building structures. The scientific community nowadays recognizes its presence and participation in the building a global response [1-3]. Different authors point out that this participation can be positive or negative, depending on a series of issues, such as type of masonry units, vertical and horizontal distribution, connection to the RC frame and openings disposition. During a seismic event, the collapse of the MIW can introduce an irregularity that can modify the building seismic response $[4,5]$. The MIW vulnerability under out-of-plane (OOP) loading demands is high and is being responsible for several fatalities and economic losses. Some research works aimed to characterizing the MIW behaviour under pure OOP loads or combined with previous inplane (IP) demands [6-9]. Characteristics such as masonry unit, mortar properties, slenderness, aspect ratio, boundary condition, and workmanship are directly related to the panel OOP's performance.

For a given infill aspect ratio, an increase in the infill slenderness results in a decreasing trend of the infill strength, as observed by Ricci et al. [10]. The failure mode was shown to shift from a yield line pattern for high slendernesses to a web-shear failure pattern for low slendernesses [11]. Concerning the effect of the IP-OOP damage interaction, several authors concluded that the IP demands reduce the OOP strength of MIW [12]. Milanesi et al. [13] studied strong infills' behaviour with prior damages due to different IP drift levels. The authors concluded that the OOP stiffness and strength could be related to previous IP damage and proposed analytical regressions.

Komaraneni et al. [14] carried out a testing campaign comprised of three half-scaled clay brick infilled RC frames subjected to a sequence of slow cyclic IP drifts demands and simultaneously to a shake tablegenerated OOP ground motions. The authors conclude that the thin walls experienced higher amplification of accelerations, and the maximum amplification was observed at the panel mid-height. Mohyeddin et al. [15] carried out a numerical study concerning the IP-OOP behaviour interaction of infilled RC frames to propose a simplified method to overcome convergence issues concerning this complex finite element analysis.

Regarding the panel aspect ratio, De Risi et al. [16] found that square and rectangular infills exhibit very different damage states, with the rectangular ones more damaged than square ones. The workmanship

\footnotetext{
* Corresponding author.

E-mail address: hrodrigues@ua.pt (H. Rodrigues).
} 


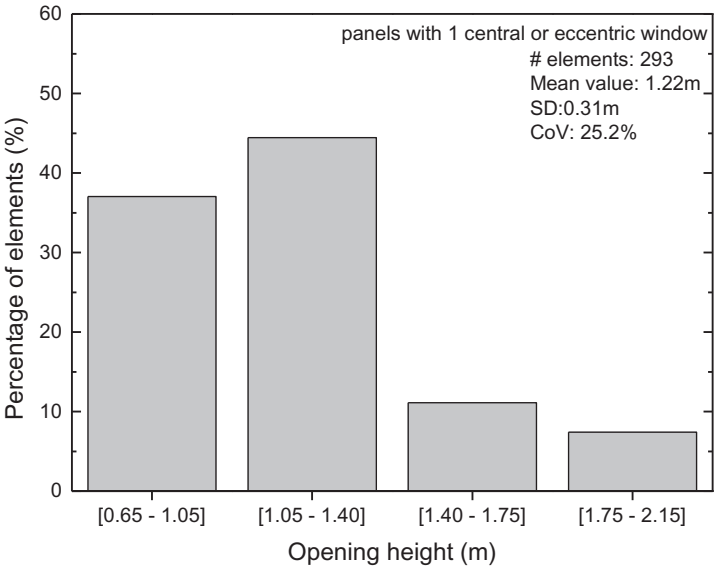

a)

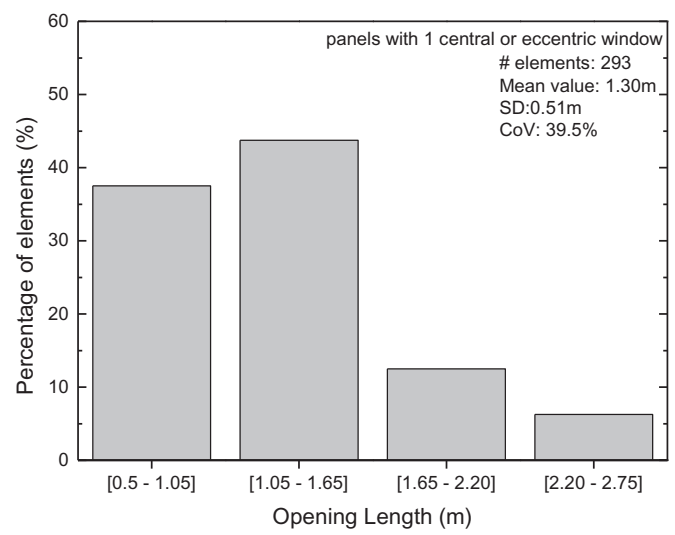

c)

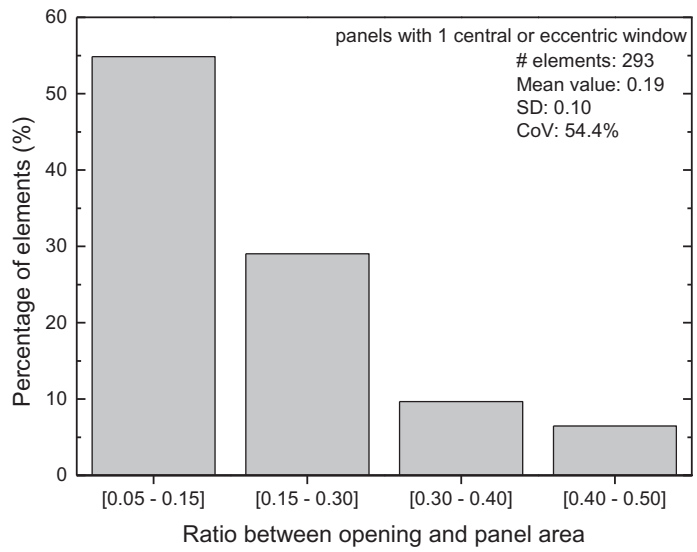

e)

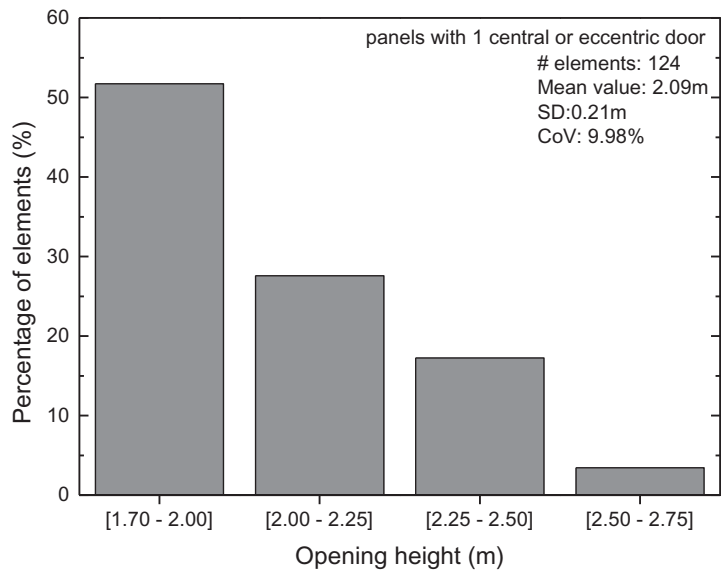

b)

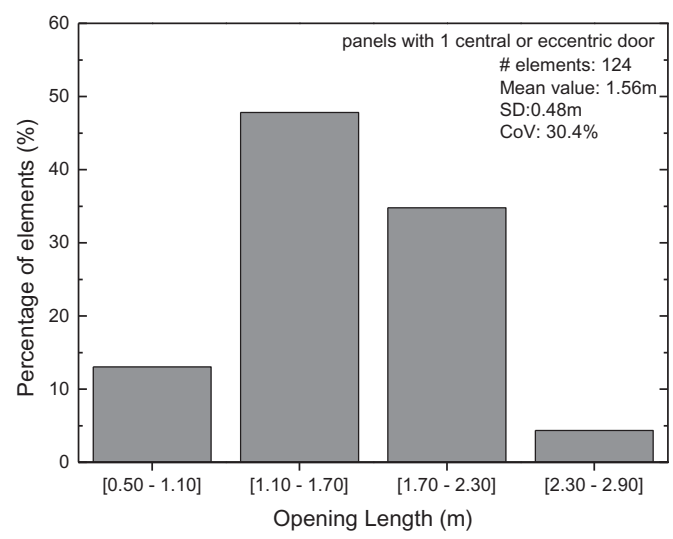

d)

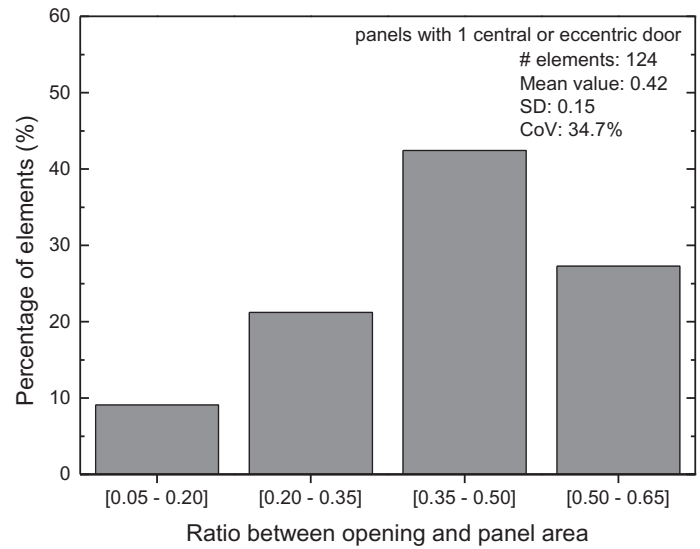

f)

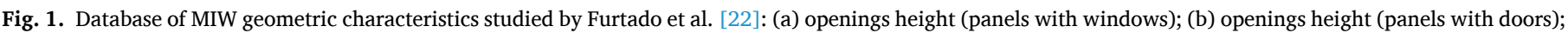

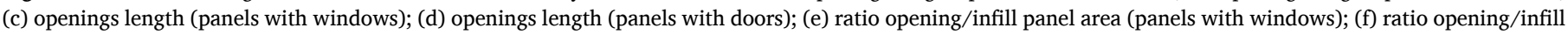
panel area (panels with doors).

was studied by Akhoundi et al. [17] and Furtado and Teresa de Risi [18]. Both studies concluded that a variation of $30 \%$ was found in the panel maximum strength and energy dissipation capacity.

Dawe and Seah [19] have studied in 1989 the effect of a central opening in the OOP behaviour of a MIW made with concrete blocks, surrounded by a steel frame. The panel geometry was $3.6 \mathrm{~m}$ in length and $2.8 \mathrm{~m}$ high and a central opening with a geometric dimension of 1.6 $\mathrm{m}$ length and $1.2 \mathrm{~m}$ height (percentage of opening equal to 19\%). From the test, the authors found that the bearing capacity was not affected by the opening. Later, Akhoundi et al. [17] tested a scaled infilled RC frame with a MIW made with hollow clay horizontal bricks, with a central window with an opening percentage equal to $12.8 \%$. The OOP loading was applied through airbags with a displacement control approach. From the test, the authors found that the opening was responsible for 


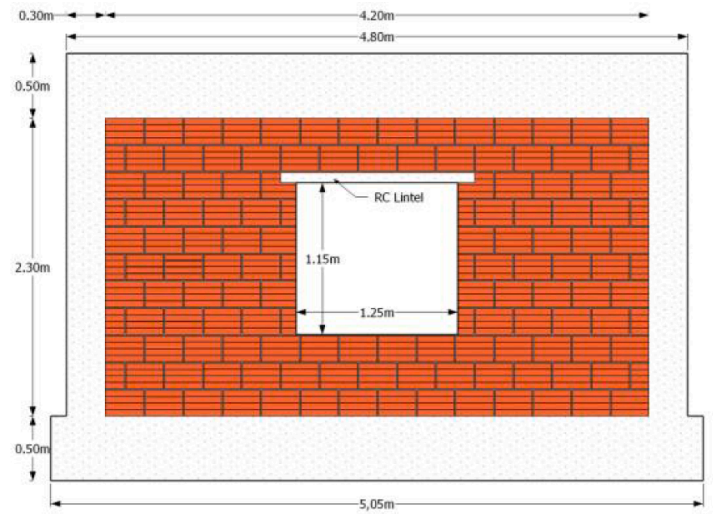

a)

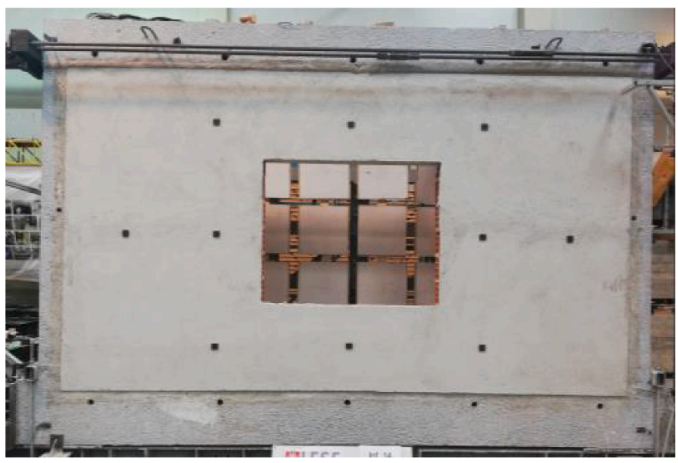

c)

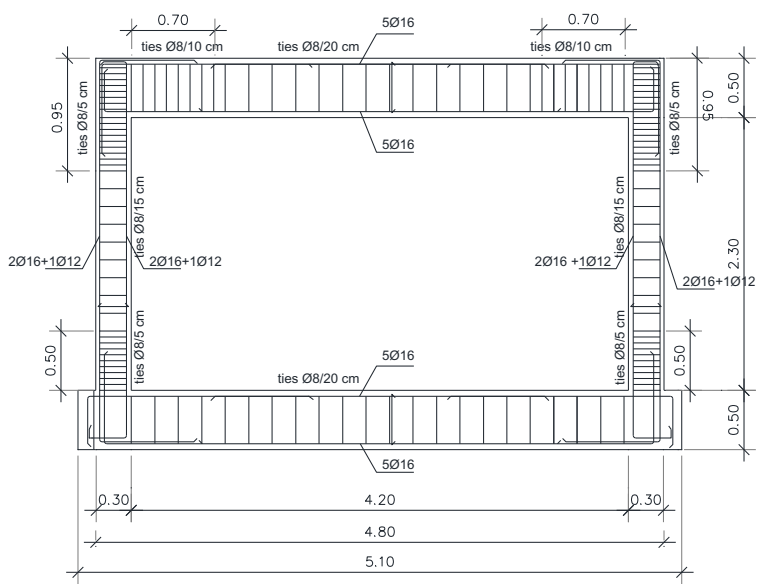

c)

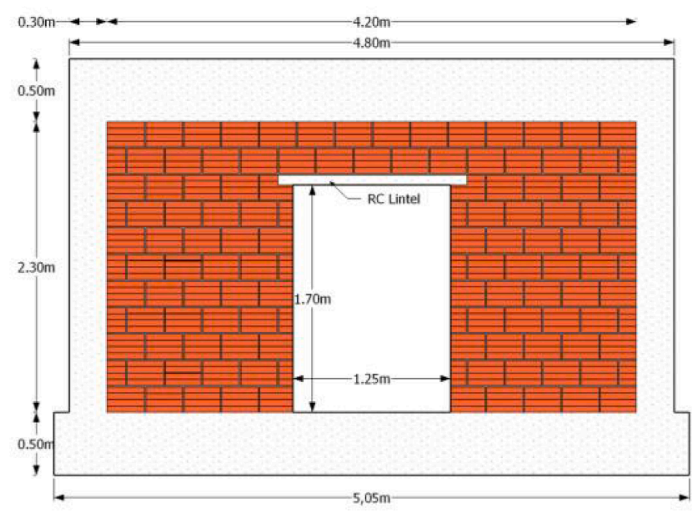

b)

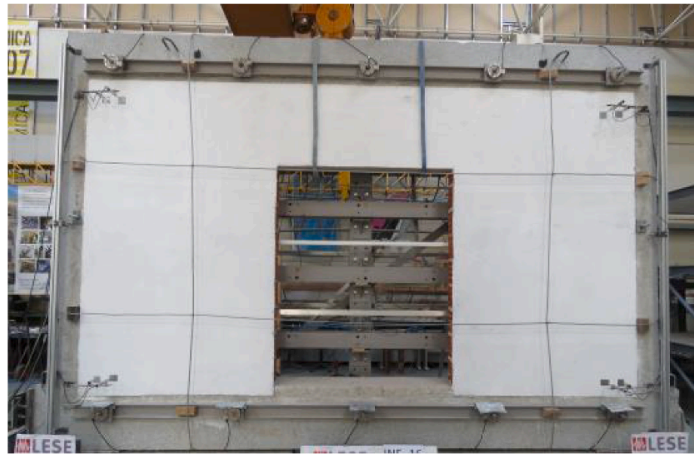

d)

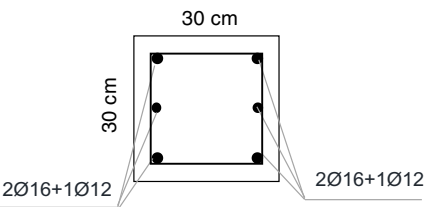

d)

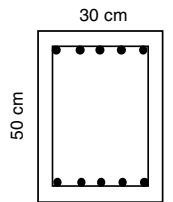

e)

Fig. 2. Infilled RC frame specimen dimensions (units in meters): (a) Inf_14_CW_IPOOP and Inf_15_CW_OOP; (b) Inf_16_CD_OOP; (c) RC frame; (d) column and (e) beam dimensions and reinforcement detailing.

reducing the panel deformation capacity. The panel strength and stiffness degradation were not affected by the opening.

Anić et al. [20] presents an extensive literature review, from which have concluded that there is a gap in the study of the effect of the openings in the MIW OOP behaviour. Furthermore, the testing of MIW with openings subjected to prior IP damage is a not covered topic yet in the literature. This gap is one of the principal motivation for the present study. More recently, Liberatore et al. [21] proposed a formula to predict the out-of-plane strength capacity of infill walls with openings. The authors also investigated numerically the effect of a gap between the infill and the top beam, from which concluded that the panel OOP capacity reduces.

This study aims to present an experimental campaign to assess the effect of the openings in the OOP behaviour of masonry infill walls. The testing campaign comprises the OOP testing of three full-scale infill walls made up of horizontal hollow clay bricks, $150 \mathrm{~mm}$ thick, with and without prior damage. The testing campaign comprised two different masonry walls typologies were tested, namely a MIW with a central window and a MIW with a central door. Details regarding the specimens are presented in Section 2. All the tests consisted of applying a semi- 
cyclic (loading-unloading-reloading) history of imposed displacements in the OOP direction using a uniformly distributed load through pneumatic actuators. The mechanical properties of the adopted materials are characterized and presented. The results will be presented in terms of damage evolution, OOP force-displacement responses, stiffness degradation and energy dissipation capacity. Tests' results are compared to each other, which assess the impact of the openings' area typology and the previous damage. The results herein achieved will enable concluding about the effect of the openings and openings area.

\section{Experimental campaign}

This section aims to provide complete information about the experimental campaign, starting from the database of MIW geometric characteristics that supported the definition of the specimen's features in Section 2.1. The specimens' details and aspects are presented in Section 2.2. After that, the material properties of each infill panels are presented in Section 2.3. Section 2.4 is provided a detailed explanation of the test setup. The loading protocol and instrumentation are given in Section 2.5 .

\subsection{Geometric characterization of the masonry infill walls in Portugal}

The specimens' geometry was defined based on the study carried out by Furtado et al. [22], in which the authors analyzed a database containing geometric properties of 1500 MIW collected from 80 buildings. The authors proposed several typologies of walls according to the number and disposition of the openings. Nine MIW typologies were identified, in which the most common ones were: typology 1 (central window) with a total percentage of $17.22 \%$, typology 2 (excentric window) corresponding to $16.55 \%$, typology 3 (central door) with a percentage of $10.42 \%$ and typology 4 (excentric door) performing a total of $7.3 \%$ of the total data. Based on these results, typology 1 and 3 were selected to be tested in this testing campaign.

Fig. 1a, c and e presents the data results concerning infill panels' geometry with windows (typologies 1 and 2). Fig. $1 \mathrm{~b}, \mathrm{~d}$ and $\mathrm{f}$ are related to the walls with doors (typologies 3 and 4 ). The parameters analyzed are the openings height, length and the ratio of the area of the openings.

From the analysis of the openings' height, it is possible to observe a clear difference between the windows and doors. Regarding the windows' height (Fig. 1a), the most common heights range between 1.05 and $1.40 \mathrm{~m}$ with a total percentage of $44 \%$, followed by $0.65-1.05 \mathrm{~m}$ (37\%) and $1.40-1.75 \mathrm{~m} \mathrm{(11 \% )} \mathrm{and} \mathrm{finally} \mathrm{by} 1.75-2.15 \mathrm{~m}(7 \%)$. The average height found was $1.22 \mathrm{~m}$, with a coefficient of variation (CoV) of $25.2 \%$. Concerning the walls with doors (Fig. 1b), about $52 \%$ of the height of the opening ranges between 1.70 and $2.00 \mathrm{~m}, 28 \%$ varies between 2.00 and $2.25 \mathrm{~m}, 17 \%$ belong to sizes ranging between 2.25 and $2.50 \mathrm{~m}$ and the remaining ones for openings height between 2.50 and $2.75 \mathrm{~m}$. The average value found was $2.10 \mathrm{~m}$, with a $\mathrm{CoV}$ equal to $9.98 \%$. From the comparison between the height of the walls' openings, it is possible to observe that the windows' average height is about $42 \%$ lower than the doors' height. Based on this, the heights selected were $1.15 \mathrm{~m}$ and $1.70 \mathrm{~m}$ for typologies 1 and 3 , respectively. The height chosen for the panel with a central door is slightly lower than the average value found in the database. The primary purpose was to extend the height used for typology 1 (central window) until the bottom beam (i.e. $1.15+0.55 \mathrm{~m}$ ).

The distribution of the length of the opening of typologies 1 and 3, is presented in Fig. 1c and d. About 48\% of the doors' length is between 1.10 and $1.70 \mathrm{~m}, 35 \%$ varies between 1.70 and $2.30 \mathrm{~m}, 13 \%$ between 0.50 and $1.10 \mathrm{~m}$ and the remaining ones between 2.30 and $2.90 \mathrm{~m}$. The average length found was $1.56 \mathrm{~m}$, with a CoV equal to $30.5 \%$. Regarding the windows' length, about $44 \%$ ranges between 1.05 and $1.65 \mathrm{~m}, 38 \%$ between 0.5 and $1.05 \mathrm{~m}, 12.5 \%$ between 1.65 and $2.20 \mathrm{~m}$ and $6 \%$ between 2.20 and $2.75 \mathrm{~m}$. An average length value of $1.30 \mathrm{~m}$ was found, with a CoV equal to $39 \%$. Based on these results, the same length was selected for typologies 1 and 3, namely $1.25 \mathrm{~m}$.

Finally, the ratio between the opening and panel area is plotted in Fig. 1e and for panels with windows and doors, respectively. Concerning the panels with windows, a ratio variation between 5 and $15 \%$ was found in $55 \%$ of the panels, $29 \%$ varied between 15 and $30 \%, 10 \%$ varied between 30 and $40 \%$ and $7 \%$ the ratio was between 40 and $50 \%$. The average ratio found was $18.83 \%$, with a CoV of $54.5 \%$. Regarding the panels with doors, a ratio variation between 35 and $50 \%$ in $42 \%$ of them was found, $28 \%$ varied between 50 and $65 \%, 21 \%$ varied between 20 and $35 \%$ and $9 \%$ the ratio is between 5 and $20 \%$. The average ratio found was $42.50 \%$, with a $\mathrm{CoV}$ of $34.7 \%$. According to the geometry defined for the panels herein tested, the opening/panel ratio is $15 \%$ and $22 \%$ for the panel with a central window and a panel with a central door, respectively.

\subsection{Description of the specimens}

The geometric dimensions of the MIWs tested are $4.20 \times 2.30 \mathrm{~m}$ (length and height, respectively) and are based on previous studies already performed for MIW without openings. Horizontal hollow clay brick units $150 \mathrm{~mm}$ thick were used, as usually found in the most common infill masonry walls in the Southern European countries. Three specimens comprise this testing campaign, namely two MIW were built with a central window, with and without prior damage due to previous in-plane test (Inf_14_CW_IPOOP and Inf_15_CW_OOP). The third specimen is a MIW with a central door subjected only to pure OOP loadings (Inf_16_CD_OOP). Concerning the relation between the results of Section 2.1 and the opening dimensions, the height of the openings was slightly reduced because the height of the frame is shorter than the real ones. The main characteristics of each model tested are the following ones:

- Inf_14_CW_IPOOP: MIW with a central window with the geometric dimensions of $1.25 \times 1.15 \mathrm{~m}^{2}$, length and height, respectively, as shown in Fig. 2a. The opening area ratio is 15\%. The model was first subjected to an in-plane test where a maximum drift of $0.3 \%$ was reached. After that, the damaged MIW was subjected to the OOP test until reaching the collapse;

- Inf_15_CW_OOP: MIW with the same typology and geometric characteristics of the specimen INF_14_CW_IPOOP. This specimen was only subjected to a pure OOP test until reaching the collapse;

Inf_16_CD_OOP: MIW with a central door with the geometric dimensions of $1.25 \times 1.70 \mathrm{~m}^{2}$, respectively, length and height, as shown in Fig. 1 b. The opening area ratio is $22 \%$. This specimen was only subjected to a pure OOP test until reaching the collapse. To assess the effect of the openings, the results obtained in these testing campaigns will be compared with the specimen Inf_08 (panel without opening and no previous IP damage) and Inf_12 (panel without opening and with prior damage due to $0.3 \%$ IP drift) results. These specimens have the same geometric dimensions, masonry units and material properties of specimens tested in this testing campaign. The only difference is the absence of opening. The specimens Inf_08 and Inf_12 were tested by Furtado [23], with the same test setup and loading protocol which will be described in Section 2.4. The specimens Inf_08 and Inf_11 are herein considered the reference specimens, from which it will be address conclusions regarding the effect of the opening. The individual results of the specimens Inf_08 and Inf_11 are detailed in [23]. The numbering of the models is related to a test sequence carried out at the Laboratory for Earthquake and Structural Engineering that belongs to the Faculty of Engineering of University of Porto.

No reinforcement was used to connect the infill panels and the surrounding RC frame, and no gaps were adopted between the panels and the frame. All the panels were built aligned with the outer side of the RC beam. The openings construction process was in agreement with the traditional techniques, which means that it was constructed an RC lintel in the top boundary of the openings. The lintel's geometric dimensions 


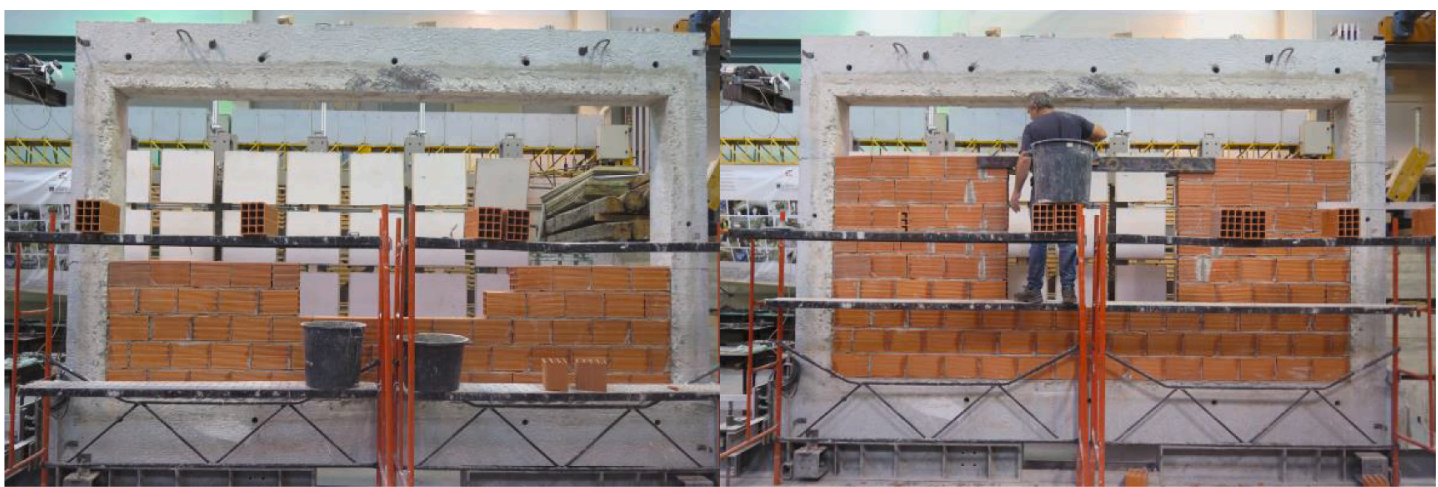

a)

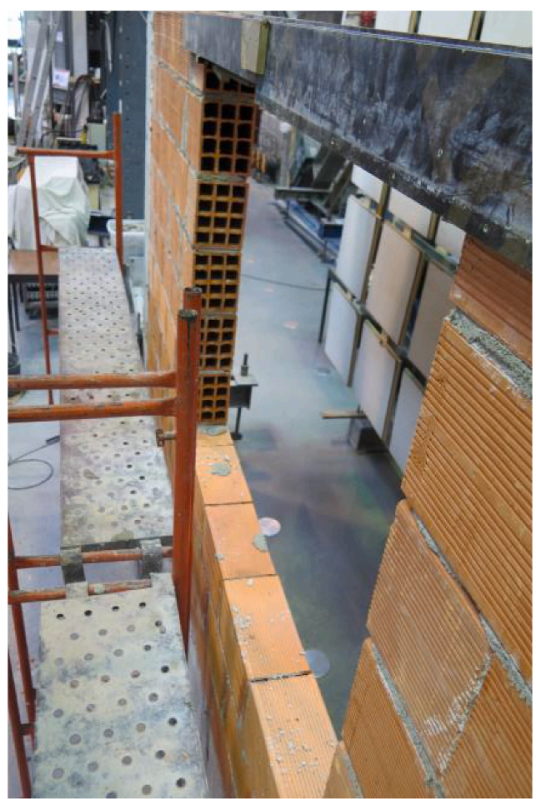

c)

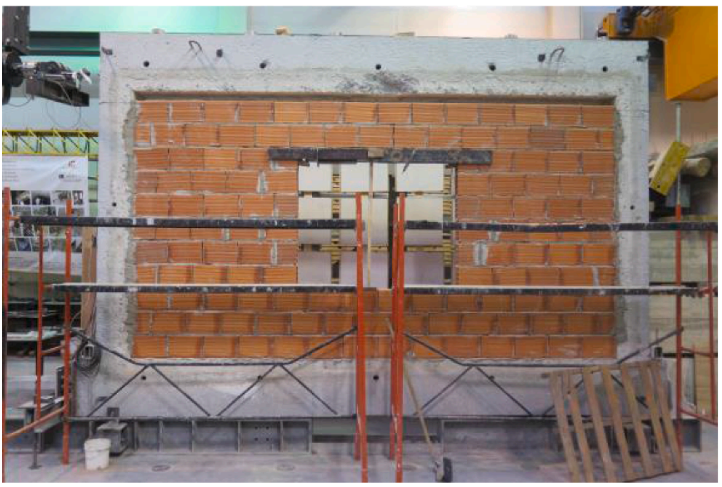

e) b)

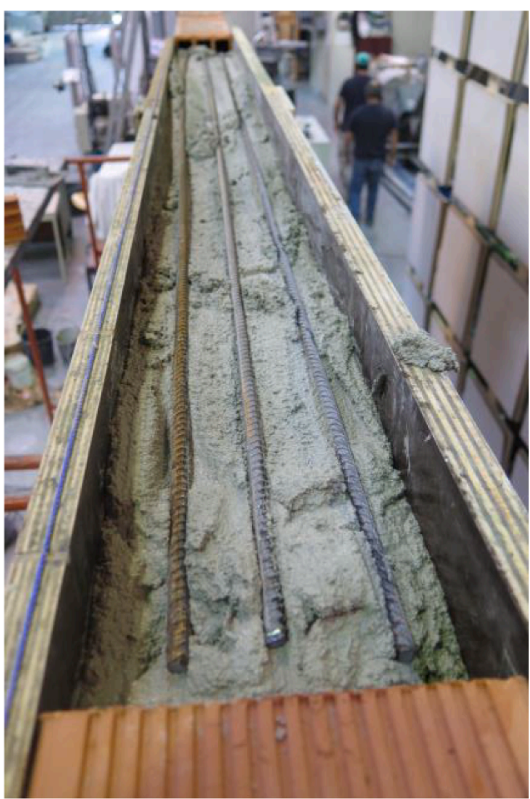

d)

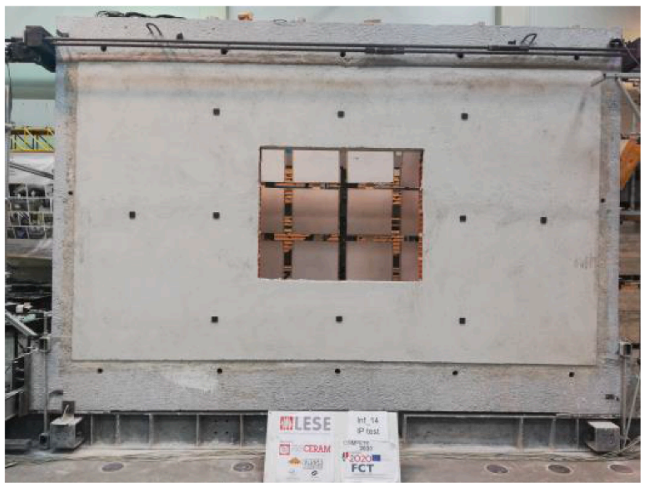

f)

Fig. 3. Construction process of the openings: (a) step 1; (b) step 2; (c) step 3; (d) detail of the RC lintel reinforcement; (e) step 4 and (f) step 5.

are $1.25 \mathrm{~m}$ length plus $0.10 \mathrm{~m}$ on each side, performing a total of $1.45 \mathrm{~m}$ and a height of $0.10 \mathrm{~m}$. Regarding the RC frame, the columns' and beams' cross-sections are $0.30 \times 0.30 \mathrm{~m}$ and $0.30 \times 0.50 \mathrm{~m}$, respectively. The columns longitudinal reinforcement are $4 \varnothing 16+2 \varnothing 12$ and a transversal reinforcement of $\varnothing 8 / / 0.05 \mathrm{~m}$ along with the plastic regions and $\varnothing 8 / / 0.15 \mathrm{~m}$ in the remaining column extension. On the other hand, the longitudinal reinforcement of the beams is $5 ø 16$. The RC frame geometry with the corresponding columns' and beams' dimensions and reinforcement detailing is shown in Fig. 2c, d, and e, respectively.

The construction procedure of the specimen Inf_14_CW_IPOOP is shown in Fig. 3. It is possible to observe that first, the three complete rows of bricks were constructed, and after that, each row length was according to the opening dimension (step 1), which means $1.48 \mathrm{~m}$ in the left and the right side and an opening length of $1.25 \mathrm{~m}$, as shown in 
Table 1

Summary of mechanical properties.

\begin{tabular}{|c|c|c|c|c|}
\hline Component & Material properties & $\begin{array}{l}\text { Average } \\
\text { value }(\mathrm{MPa})\end{array}$ & $\begin{array}{l}\mathrm{CoV} \\
(\%)\end{array}$ & $\begin{array}{l}\text { SD } \\
(\mathrm{MPa})\end{array}$ \\
\hline \multirow[t]{2}{*}{ Concrete } & Compressive strength & 22.85 & 6.1 & 0.88 \\
\hline & Elastic modulus & 24300 & 0.9 & 210 \\
\hline \multirow[t]{8}{*}{ Steel rebars } & Elastic Modulus & & & \\
\hline & $\phi 8 \mathrm{~mm}$ & 198000 & 5.4 & 10692 \\
\hline & $\phi 10 \mathrm{~mm}$ & 192000 & 6.2 & 11904 \\
\hline & $\phi 16 \mathrm{~mm}$ & 187000 & 2.1 & 3927 \\
\hline & Elastic Modulus & & & \\
\hline & $\phi 8 \mathrm{~mm}$ & 535 & 2.2 & 11.8 \\
\hline & $\phi 10$ mm & 526 & 3.5 & 18.4 \\
\hline & $\phi 16$ mm & 532 & 3.2 & 17.1 \\
\hline $\begin{array}{l}\text { Masonry } \\
\text { unit }\end{array}$ & Compressive strength & 1.04 & 23.6 & 0.24 \\
\hline \multirow[t]{6}{*}{$\begin{array}{l}\text { Masonry } \\
\text { walls }\end{array}$} & $\begin{array}{l}\text { Masonry walls compressive } \\
\text { strength perpendicular to the } \\
\text { horizontal holes }\end{array}$ & 1.09 & 12.8 & 0.14 \\
\hline & $\begin{array}{l}\text { Elastic modulus perpendicular } \\
\text { to the horizontal holes }\end{array}$ & 1975 & 36.7 & 719 \\
\hline & Diagonal tensile strength & 0.65 & 22.2 & 0.14 \\
\hline & Shear straining & 996 & 8.9 & 88.7 \\
\hline & $\begin{array}{l}\text { Flexural strength parallel to the } \\
\text { bed-joints }\end{array}$ & 0.22 & 17.6 & 0.04 \\
\hline & $\begin{array}{l}\text { Flexural strength } \\
\text { perpendicular to the bed-joints }\end{array}$ & 0.30 & 7.90 & 0.02 \\
\hline
\end{tabular}

Fig. 3a. After that, six rows of bricks were built, which are equivalent to the opening height (step 2), as shown in Fig. 3b. At the sixth row middleheight, it was made an RC lintel (step 3), shown in Fig. 3c, which comprised three reinforcement bars of $\phi 6 \mathrm{~mm}$ diameter, as shown in Fig. 3d, with a total length equal to $1.65 \mathrm{~m}$. One day after the casting of the lintel, it was carried out the construction of the remaining top part of the MIW (step 4), shown in Fig. 3e. The top boundary of the panel was fully mortared on the second day after the construction of the lintel (step 5), as presented in Fig. 3f. The plaster was applied seven days after the MIW construction. The same procedure was adopted for all the specimens.

\subsection{Material properties}

Material mechanical characterization was performed to collect information about the RC frame's properties (concrete and steel samples), masonry units, small masonry walls, and plaster. Starting from the RC frame properties, compressive strength tests were performed in six cylindrical specimens collected during the casting of the frame, which resulted in an average cubic compressive strength $\left(\mathrm{f}_{\mathrm{cm}, \mathrm{cyl}}\right)$ equal to 22.85 MPa with a standard deviation (SD) of $0.88 \mathrm{MPa}$ and a coefficient of variation $(\mathrm{CoV})$ of $6.1 \%$. The concrete average elastic modulus obtained was $24.3 \mathrm{GPa}$ with an SD of $0.21 \mathrm{GPa}$ and a $\mathrm{CoV}$ equal to $0.9 \%$. Concerning the steel reinforcement bars, three different bar diameters were used, namely $\varnothing 6 \mathrm{~mm}, \varnothing 10 \mathrm{~mm}$ and $\varnothing 16 \mathrm{~mm}$. Three samples of each were taken from each diameter bar and tested according to [24]. From the test results, the yield strength and young modulus of the steel bars are $535 \mathrm{MPa}$ and 198GPa regarding the $\phi 8 \mathrm{~mm}$ bars, $526 \mathrm{MPa}$ and $192 \mathrm{GPa}$ regarding the $\phi 10 \mathrm{~mm}$ bars and $532 \mathrm{MPa}$ and $187 \mathrm{GPa}$ regarding the $\phi 16 \mathrm{~mm}$ bars, respectively.

Compressive strength tests were carried out on the masonry units along with the direction perpendicular to the horizontal holes, which resulted in the average value of $1.04 \mathrm{MPa}$, a CoV equal to $23.6 \%$ and an $\mathrm{SD}$ of $0.24 \mathrm{MPa}$. Compression strength tests perpendicular to the horizontal bed joints were carried out in masonry walls, according to EN 1052-1 [25], where it was determined the masonry compressive strength and elastic modulus. Diagonal tensile strength tests were performed according to RILEM TC-76-LUM [26], from which it was determined the diagonal tensile strength and shear straining. Finally, flexural strength tests parallel and perpendicular to the horizontal bed joints were carried out according to EN 1052-2 [27]. The summary of the
Table 2

Results from flexure and compressive strength tests on mortar specimens.

\begin{tabular}{|c|c|c|c|c|}
\hline \multirow[t]{2}{*}{ Specimen } & \multicolumn{2}{|c|}{$\begin{array}{l}\text { Mortar used in the wall } \\
\text { construction }\end{array}$} & \multicolumn{2}{|c|}{ Mortar used for plastering } \\
\hline & $\begin{array}{l}\text { Flexure } \\
\text { strength } \\
(\mathrm{MPa})\end{array}$ & $\begin{array}{l}\text { Compressive } \\
\text { strength } \\
(\mathrm{MPa})\end{array}$ & $\begin{array}{l}\text { Flexure } \\
\text { strength } \\
(\mathrm{MPa})\end{array}$ & $\begin{array}{l}\text { Compressive } \\
\text { strength } \\
\text { (MPa) }\end{array}$ \\
\hline Inf_14_CW_IPOOP & $\begin{array}{l}2.43 \text { (CoV: } \\
26.40 \% \text {; } \\
\text { SD: } 0.64 \\
\text { MPa) }\end{array}$ & $\begin{array}{l}6.58(\mathrm{CoV}: \\
39.40 \% \text {; SD: } \\
2.60 \mathrm{MPa})\end{array}$ & $\begin{array}{l}1.54 \text { (CoV: } \\
3.60 \% \text {; } \\
\text { SD: } 0.06 \\
\text { MPa) }\end{array}$ & $\begin{array}{l}4.22 \text { (CoV: } \\
5.20 \% \text {; SD: } \\
0.22 \mathrm{MPa})\end{array}$ \\
\hline Inf_15_CW_OOP & $\begin{array}{l}1.66 \text { (CoV: } \\
5.40 \% \text {; } \\
\text { SD: } 0.09 \\
\text { MPa) }\end{array}$ & $\begin{array}{l}4.22 \text { (CoV: } \\
13.20 \% \text {; SD: } \\
0.56 \mathrm{MPa})\end{array}$ & $\begin{array}{l}1.36 \text { (CoV: } \\
14.80 \% \text {; } \\
\text { SD: } 0.20 \\
\text { MPa) }\end{array}$ & $\begin{array}{l}3.80 \text { (CoV: } \\
8.40 \% ; \mathrm{SD}: \\
0.32 \mathrm{MPa})\end{array}$ \\
\hline Inf_16_CD_OOP & $\begin{array}{l}1.46 \text { (CoV: } \\
5.20 \% \text {; } \\
\text { SD: } 0.08 \\
\text { MPa) }\end{array}$ & $\begin{array}{l}4.09 \text { (CoV: } \\
6.20 \% \text {; SD: } \\
0.25 \mathrm{MPa})\end{array}$ & $\begin{array}{l}1.47 \text { (CoV: } \\
6.60 \% \text {; } \\
\text { SD: } 0.97 \\
\text { MPa) }\end{array}$ & $\begin{array}{l}3.92 \text { (CoV: } \\
4.30 \% \text {; SD: } \\
0.22 \mathrm{MPa})\end{array}$ \\
\hline
\end{tabular}

mechanical properties is presented in Table 1.

Additionally, flexural and compression strength mortar tests were carried out in mortar specimens, according to EN 196-2006 [28]. Six samples, $40 \times 40 \times 160 \mathrm{~mm}$ were tested for each infill panel build (both mortar used to build the panel and mortar used for strengthening). The significant results are summarized in Table 2. From the results, it is possible to observe that the mortar's compressive strength for constructing the infill panels is around $5 \mathrm{MPa}$ as expected, being the highest value achieved by the specimen Inf_14_CW_IPOOP with $6.58 \mathrm{MPa}$ and the lowest by Inf_16_CD_OOP with $4.09 \mathrm{MPa}$, which is $38 \%$ lower. Concerning the flexural strength, the results are around $2 \mathrm{MPa}$, being the highest one $2.43 \mathrm{MPa}$ obtained again by Inf_14_CW_IPOOP and the weakest $1.46 \mathrm{MPa}$ (Inf_16_CD_OOP), which is $40 \%$ lower. The mortar results for the plaster present similar trends, being the highest values achieved for the specimen Inf_14_CW_IPOOP and the weakest for Inf_16_CD_OOP.

\subsection{Description of the test setup}

\subsubsection{Out-of-plane test}

The OOP test of all the specimens consisted in the application of a distributed OOP loading through several pneumatic actuators that mobilized the entire infill panel surface with wood plates $\left(50 \times 50 \mathrm{~cm}^{2}\right)$ (one per actuator) placed between the actuators and the panel, as shown in Fig. 4a and b. Between the infill wall's surface and the wood panel, a $7 \mathrm{~mm}$ cork plate was included to help applying the load in a distributed manner avoiding stress concentrations. All the pneumatic actuators are linked to four horizontal steel elements, which react against five vertical steel elements. The horizontal steel elements are coupled with hinged devices that allow lateral sliding. The steel reaction structure is attached to the RC frame in twelve points ( 5 in the bottom beam, 5 in the top beam, and 2 in middle-height columns) with steel bars that are coupled with load cells to allow monitoring the OOP loadings. This selfequilibrated system balances the transmission of the OOP loadings to the reaction frame.

This load application approach is innovative in the literature since it can apply uniform OOP loadings in MIW with openings, due to the possibility of removing some of the pneumatic actuators according to the MIW configuration and dimensions. For example, Fig. $4 \mathrm{c}$ shows the test setup view used for the specimens Inf_14_CW_IPOOP and Inf_15_CW_OOP, in which six pneumatic actuators located in the centre of the panel (location of the opening) were removed. Due to the geometry of the specimen Inf_16_CD_OOP, nine pneumatic actuators were removed for the OOP test, as shown in Fig. 4d. The general view of the test setup adopted for the specimen with central window (Inf_14_CW_IPOOP and Inf_15_CW_OOP) and central door (Inf_16_CD_OOP) is shown in Figs. 5 and 6, respectively. The OOP tests 


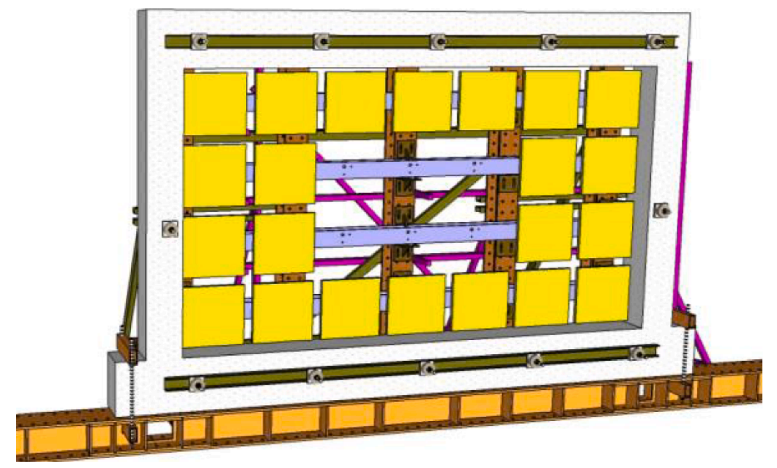

a)

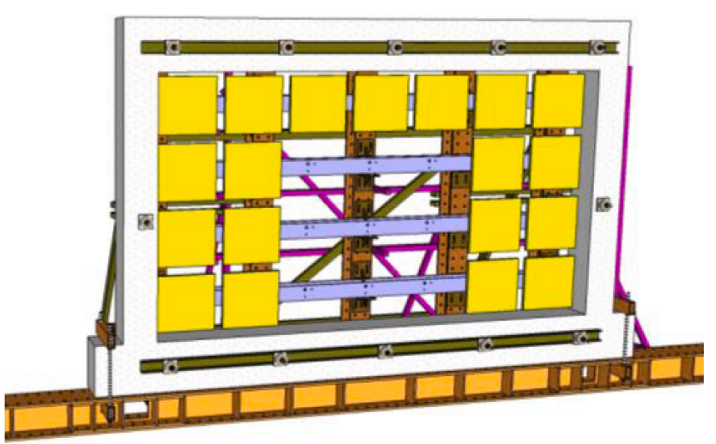

b)

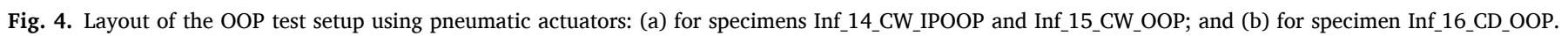

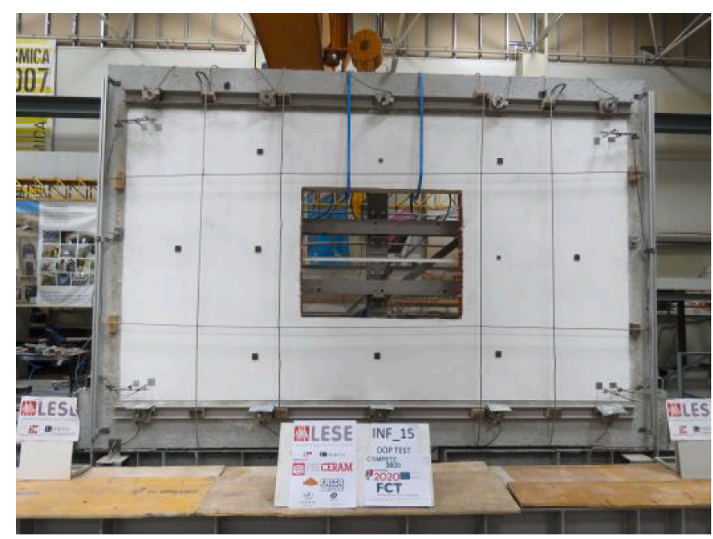

a)

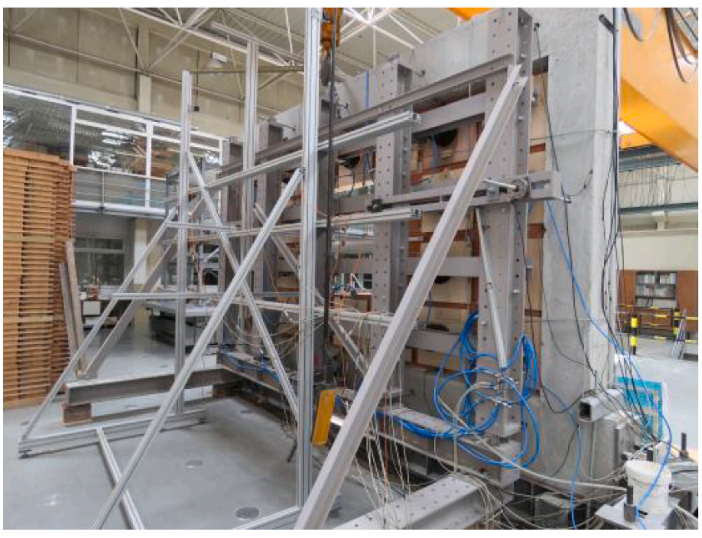

c)

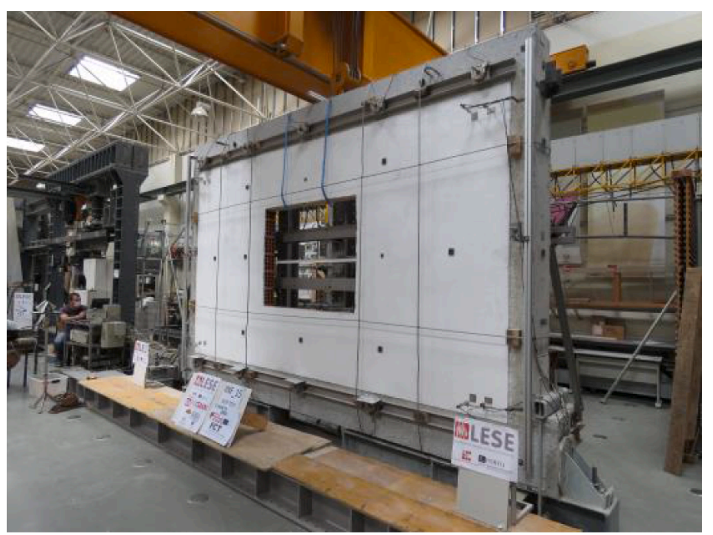

b)

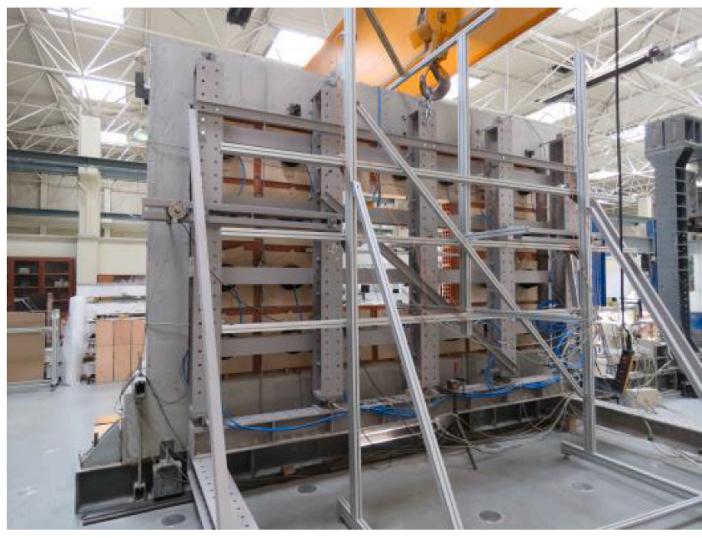

d)

Fig. 5. General view of the OOP test setup for specimen Inf_15_CW_OOP: (a) Front view; (b) lateral view; (c) lateral back view and (d) backside view.

of all the specimens were using the test setup herein detailed in this section.

One of the advantages of this test setup is the possibility of placing the instrumentation in the backside of the reaction structure, allowing performing OOP tests until the panel collapse without damaging any equipment.

The procedure adopted is a displacement control test, in which a displacement history controlled in a defined point of the wall. The pneumatic actuators are air-filled with the same pressure (controlled with a pressure valve) and apply a distributed loading to reach the target displacement in the selected point. It was established the same reference central point that was previously used for the panels Inf_08 (no opening, no previous IP damage) and Inf_11 (no openings, previous IP drift of $0.3 \%$ ) to have the possibility of a direct comparison between specimens. Since the selected point is located in the opening area, the strategy adopted to measure the displacement consisted of using a steel tube profile fixed in the opening's two lateral extremities, as shown in, as shown in Fig. 7. The tube profile was cut, along the longitudinal direction, around the connector, which linked it to the panel surface. A stiff tube was selected, preventing the bending development and ensuring 


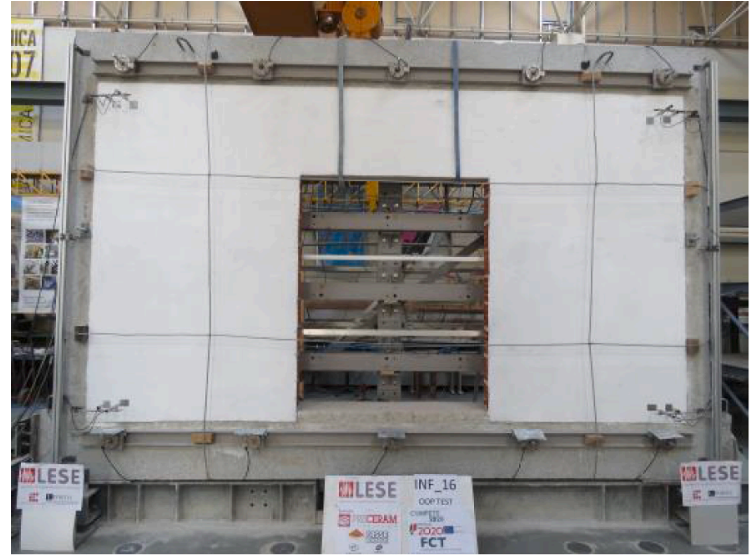

a)

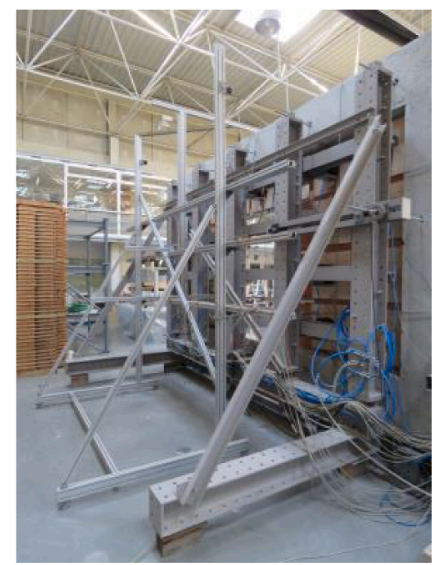

c)

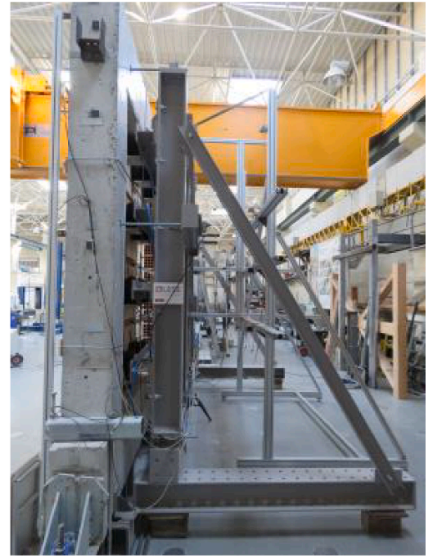

b)

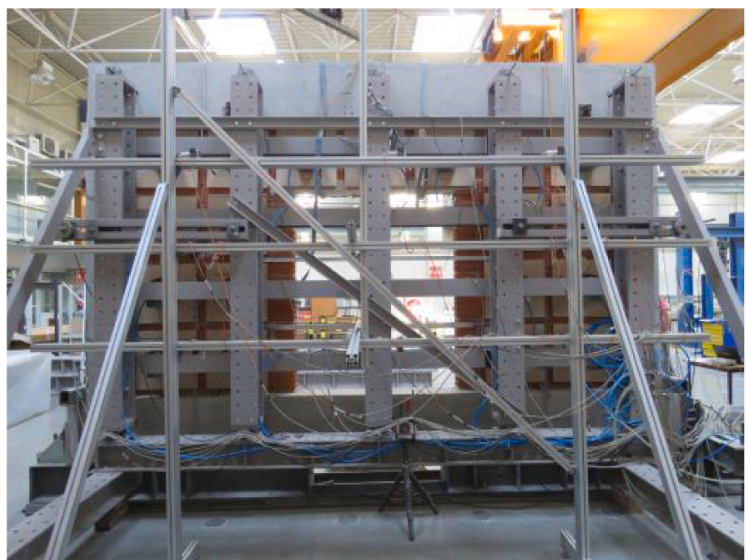

d)

Fig. 6. General view of the OOP test setup for specimen Inf_16_CD_OOP: (a) Front view; (b) profile view; (c) lateral view and (d) back view.

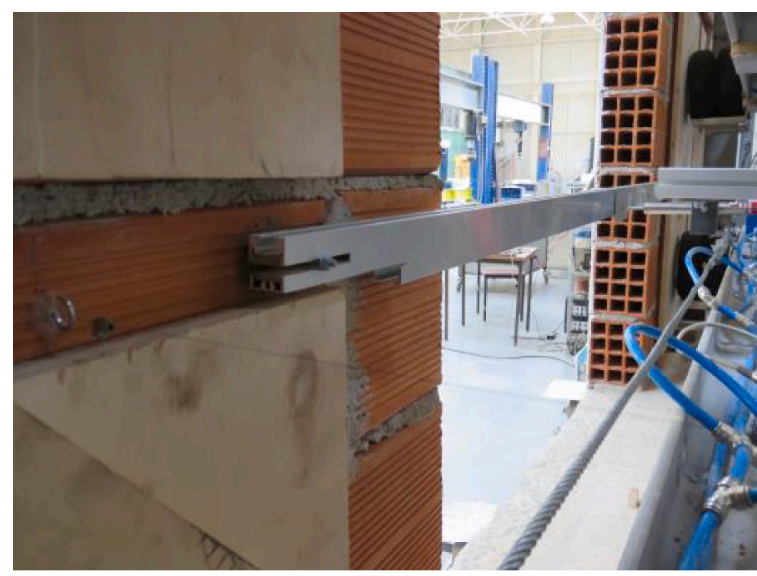

a)

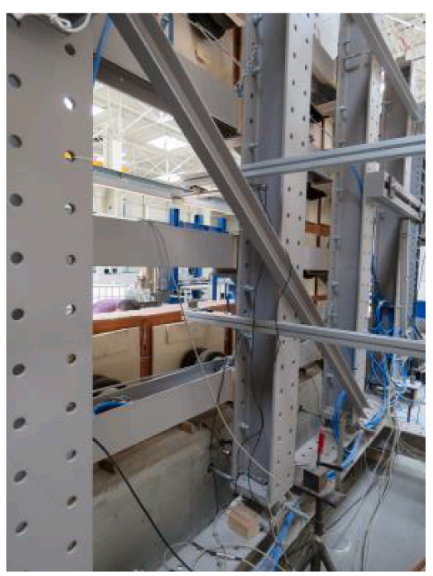

b)

Fig. 7. Measurement of the control point: (a) detail of the tube steel profile; and (b) lateral view.

that the displacement should be the same at the centre of the opening's vertical edges.

\subsubsection{In-plane test}

The quasi-static IP cyclic test consisted of applying a horizontal force at half the height of the RC frame's upper beam through a hydraulic actuator with a capacity of approximately $500 \mathrm{kN}$ and $\pm 150 \mathrm{~mm}$ travel. The hydraulic actuator is connected to a steel reaction structure. The horizontal force transmission to ensure full-cycle tests were performed using two steel profiles positioned on the top beam's extremities linked together through four dywidag bars $(\varnothing 27 \mathrm{~mm})$ prestressed, resulting in a beam compression of about $170 \mathrm{kN}$. The quasi-static cyclic test scheme 


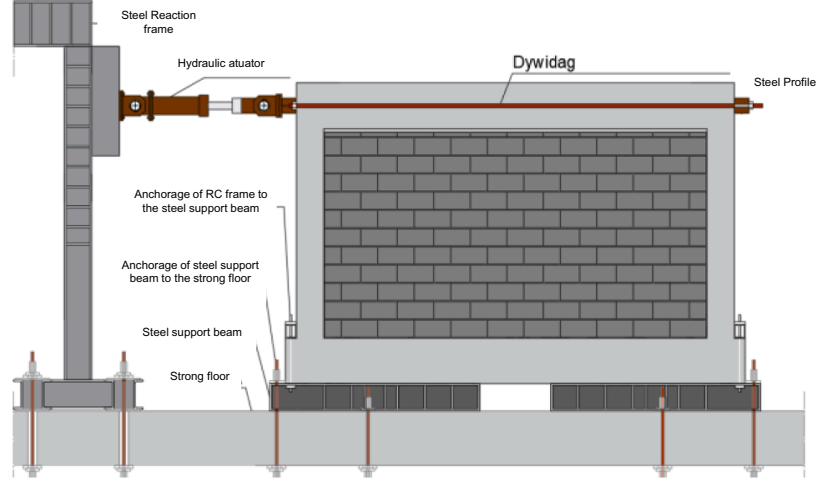

a)

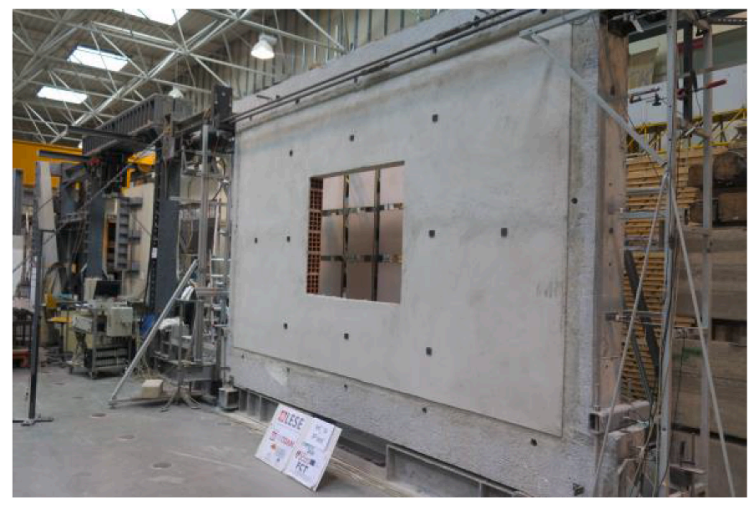

b)

Fig. 8. View of the IP test setup: (a) Schematic layout; (b) Front view. (Instrumentation: schematic front layout (a) specimens Inf_14_CW_IPOOP and Inf_15_CW_OOP; (b) specimen Inf_16_CD_OOP.)

in the plane is shown in Fig. 7. It was used a steel structure at the back of the $\mathrm{RC}$ frame, linked in two points of the frame top beam. The primary goal was to avoid OOP displacement or rotation of the structure during the test.

The frame's base IP and OOP displacement were restricted using a steel profile attached to the Laboratory strong slab.

\subsection{Instrumentation and loading protocol}

Several linear variable displacement transducers (LVDT's) were used to measure the panel's OOP displacements along five horizontal and vertical alignments (twenty-five in the case of the specimens Inf_14_CW_IPOOP and Inf_15_CW_OOP, and twenty-three in the case of Inf_16_CD_OOP). The wall detachment from the surrounding corners was measured by LVDT's placed in the infill plane-frame interface. Six displacement transducers monitored the OOP displacements of columns and beams. Additionally, the top beam's vertical displacements were measured by one LVDT placed at mid-span to monitor the evolution of possible arching mechanism. The displacement transducer "BV" placed in the top of the beam was used to measure the vertical beam displacement throughout the OOP tests. The schematic layout of the instrumentation used for each specimen is shown in Fig. 8.

The loading protocol is based on the protocol used in the previous tests [29] and consisted of the application of several half-cyclic OOP displacements (loading-unloading-reloading) that were imposed with steadily increasing displacement levels, targeting the following nominal peak displacements at the control node located in the centre of the panel (sensor W13): 0.5, 1, 1.5, 2, 2.5, 3.5; 5; 7.5; $10 \mathrm{~mm}$; and then 5 by $5 \mathrm{~mm}$ up to a maximum OOP displacement of $120 \mathrm{~mm}$ (largest capacity of the

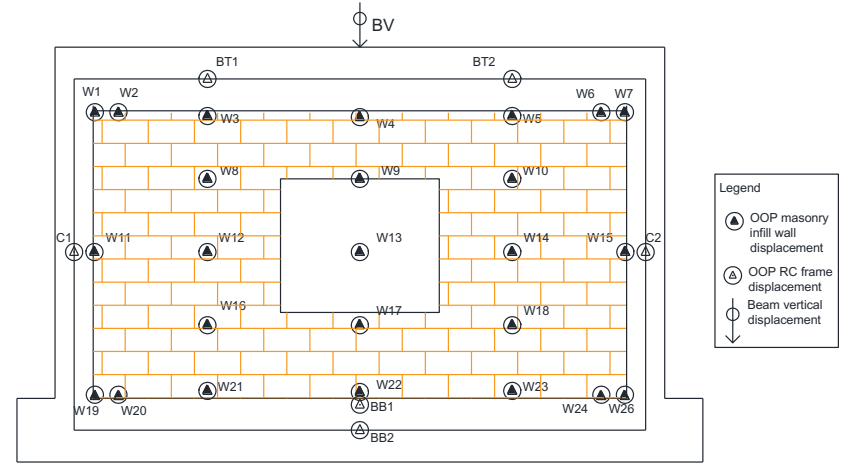

a)

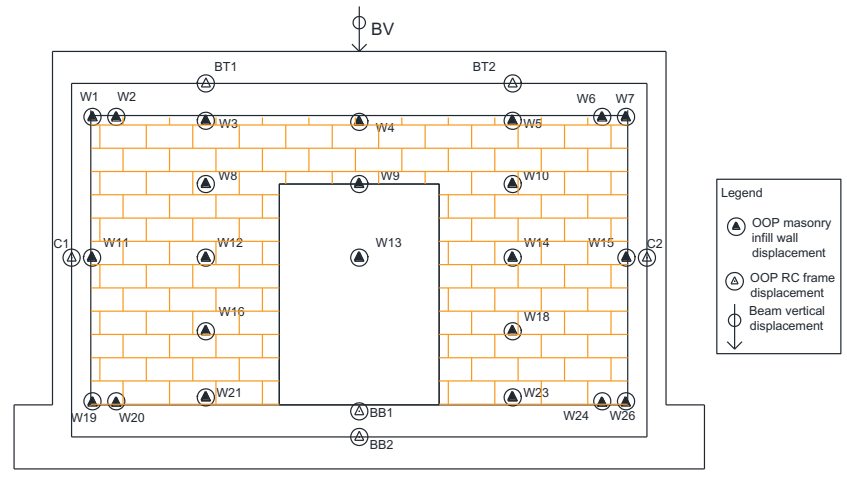

b)

Fig. 9. Specimen Inf_14_CW_IPOOP - IP test: (a) Cracking pattern (0.1\%); (b) Cracking pattern $(0.2 \%)$; (c) Cracking pattern $(0.3 \%)$ and (d) force-displacement curve.

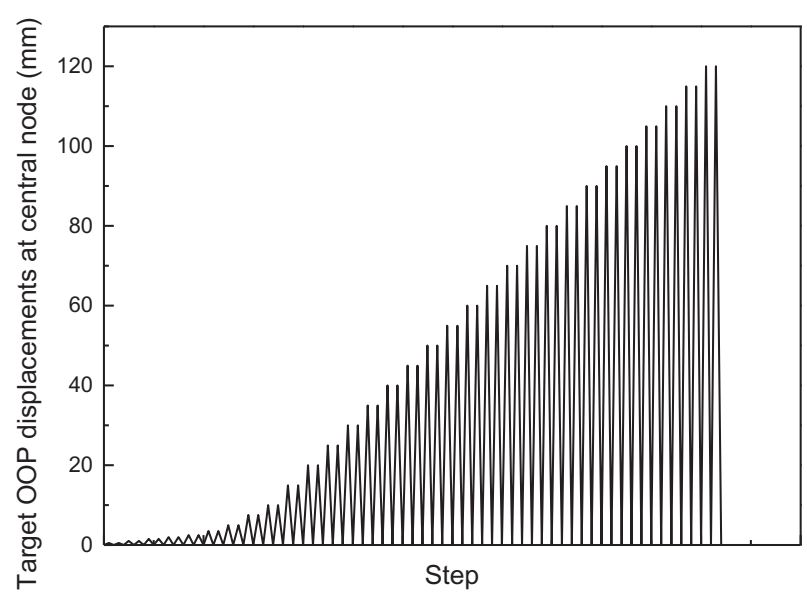

Fig. 10. Displacement history used in the OOP tests. (Specimen Inf_14_CW_IPOOP - OOP test: (a) Cracking pattern before the collapse; (b)-(e) collapse mechanism sequence and (f) Collapsed parts of the panel.)

pneumatic actuators). Two half-cycles were repeated for each lateral deformation demand level. No axial load was applied in the top of the adjacent RC columns. The displacement history is presented in Fig. 10.

\section{Experimental results}

The experimental results are presented and analyzed for each test in terms of OOP load $\left(\mathrm{F}_{\mathrm{OOP}}\right.$ ) versus OOP displacement in the infill panel 


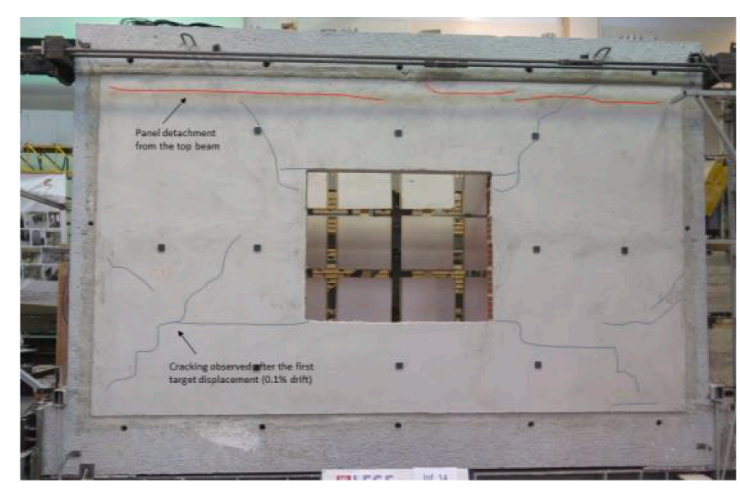

a)

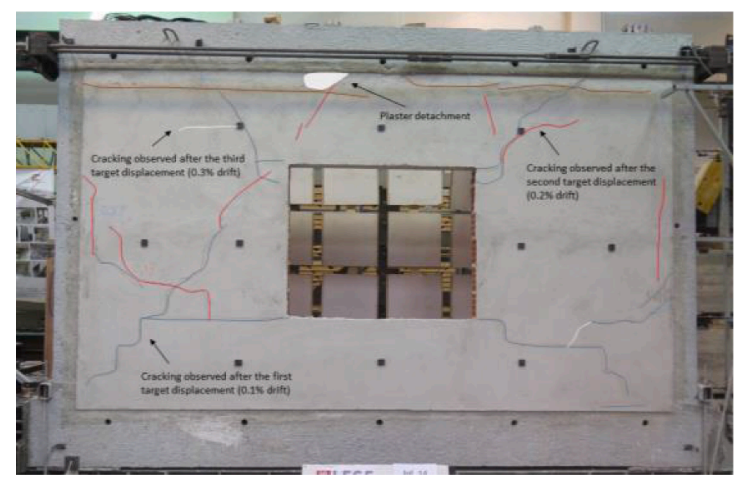

c)

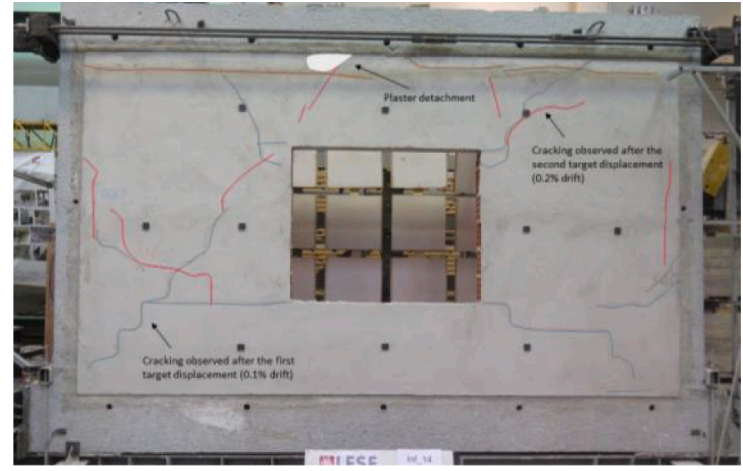

b)

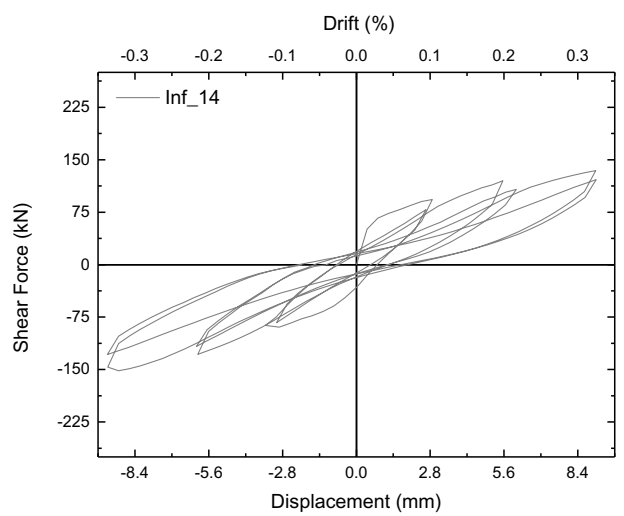

d)

Fig. 11. Specimen Inf_14_CW_IPOOP - OOP test: a) Force-displacement curve; and (b) force - vertical beam displacement.

centre $\left(\mathrm{d}_{\mathrm{OOP}}\right)$. A detailed report of the damage evolution from the first observed cracks on the infill panel surface until the end of the test is presented. The OOP drift was computed related to the panel control node. Some considerations will be drawn regarding the first cracking (instant in which occur the first crack), maximum peak load and ultimate residual load (last instant of the test). It was also assumed a conventional failure that corresponds to a $20 \%$ strength drop in the postpeak stage.

\subsection{Specimen Inf_14_CW_IPOOP (OOP test $w /$ prior damage - $0.3 \%$ IP drift)}

\subsubsection{In-Plane test}

The first test consisted of the application of a horizontal displacement in the top of the frame. The primary purpose was to introduce a minimum level of damage on the MIW. Two full cycles were carried out for each one displacements peak chosen, namely: 2.8 (0.1\% drift), 5.6 $(0.2 \%$ drift $)$ and $8.4 \mathrm{~mm}(0.3 \%$ drift $)$.

Fig. 9a shows the cracking pattern observed for the drift level $(0.1 \%$ drift). It is possible to identify the development of crackings from the corners of the opening. Regarding the left side in the bottom of the infill panel, a horizontal crack is visible from the opening and another one diagonal from the bottom corner of the wall. The MIW- top beam detachment occurred, and the cracking due to this detachment is evidenced in red.

Fig. 9b shows the cracking pattern observed after the second peak ( $0.2 \%$ drift), highlighted in brown. The evolution of the cracks already that already appeared in the previous target displacement is visible. A new crack is visible along with the RC lintel contour at the top of the opening. Plastering detachment occurred due to the lateral movement in the MIW-frame interface at the top of the wall. Additional cracks were also reported in the MIW-columns interface (near the middle-height region).

Finally, no significant differences can be noticed regarding the stage of $0.3 \%$ drift. It was only observed a larger thickness of the existing cracks, as shown in Fig. 9c.

The force-displacement response curve is presented in Fig. 9d. The initial panel stiffness was about $127 \mathrm{kN} / \mathrm{mm}$. There was a slight strength increase along with the increment of the IP displacements. The maximum peak load was achieved for the IP drift of $0.30 \%$, reaching $134 \mathrm{kN}$ and $-151 \mathrm{kN}$, in the positive and negative branch, respectively. Smooth strength degradation is visible when comparing the 1 st and 2nd cycles envelopes.

\subsubsection{Out-of-plane test}

The out-of-plane load was applied after the in-plane test, according to the protocol described before. The first crack occurred for the OOP displacement of $6.3 \mathrm{~mm}$ (drift equal to $0.55 \%$ ) and consisted of a vertical one on the wall's right side. The force corresponding to the first crack development was about $27.01 \mathrm{kN}$. After, the deformation was concentrated along the regions next to the opening. In particular, a panel sliding next to the opening right-side caused more massive OOP displacements. Fig. 10a shows the cracking pattern of the wall for an OOP displacement of $20 \mathrm{~mm}$. Right after this point, it started to develop a failure mechanism, shown in Fig. 10b-f, in which the right part of the panel split into three parts. This deformation triggered the panel's detachment from the top beam, and the collapse of the wall. The portion of the panel above the RC lintel did not collapse since the left side of the MIW remained in stable conditions and with limited deformation (only evidencing larger cracks). 


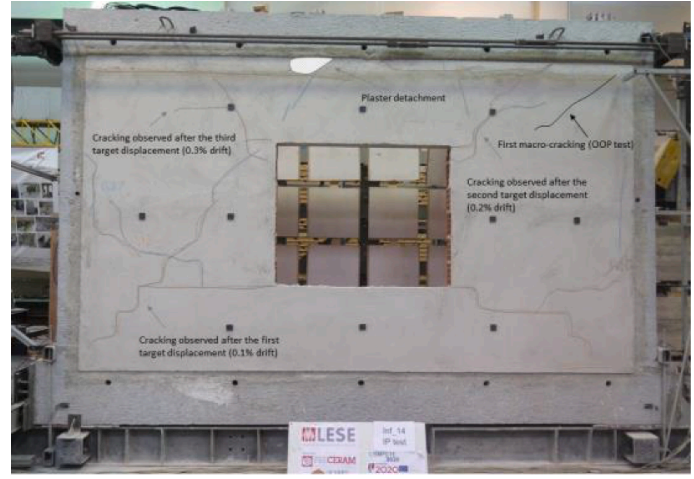

a)

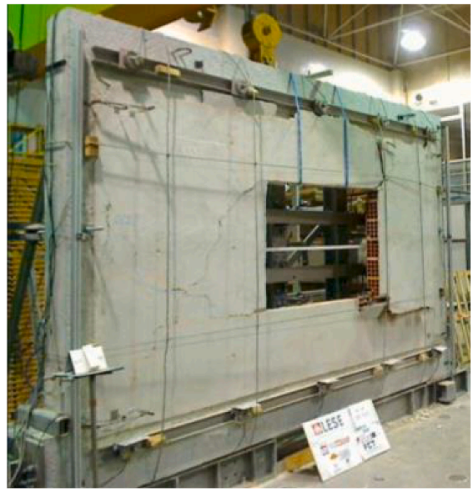

c)

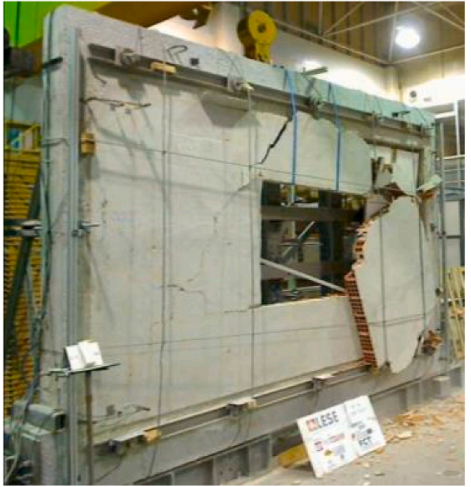

e)

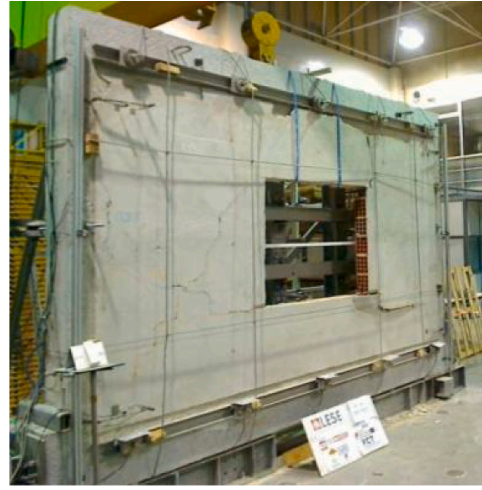

b)

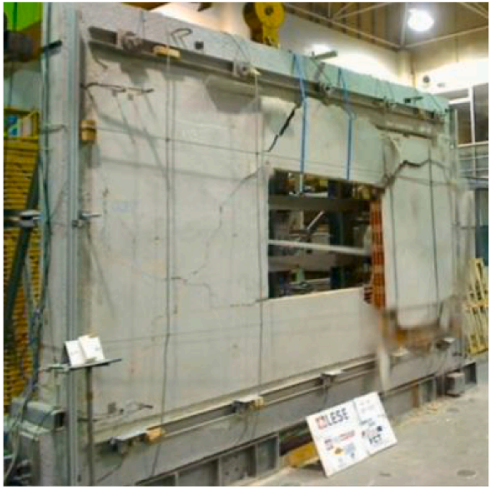

d)

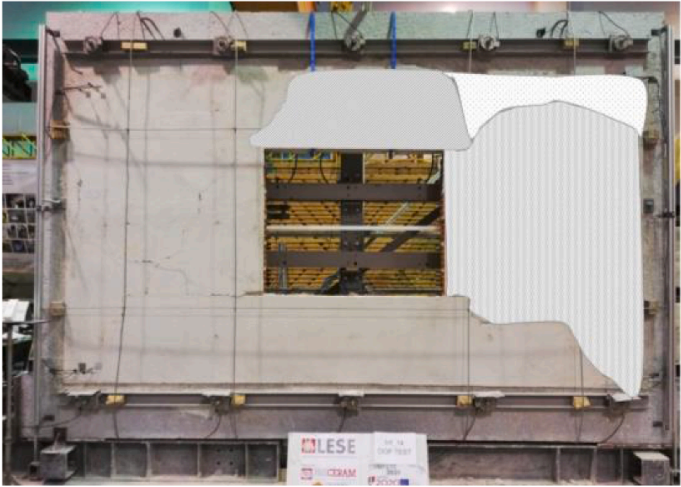

f)

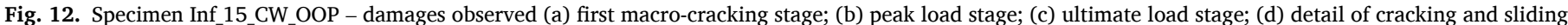
(front view); (e) back view, and (f) detail of the damages near to the opening.

It was also possible to observe that most of the OOP deformation occurred along with the left and right boundary region of the opening, since the lack of continuity introduced some fragility to the panel compared with the bottom and top panel stripe that behaved acting as an arching mechanism. The panel-top beam interface detachment occurred for small displacement values and was more pronounced in the panel middle-length.

From the force-displacement curve, plotted in Fig. 11a, it is possible to identify several parameters that allow understanding the panel's global behaviour. The initial stiffness was $21.38 \mathrm{kN} / \mathrm{mm}$, and the OOP strength increased until $23.41 \mathrm{kN}$, when it occurred the first macro-crack presented in Fig. 10a. The OOP displacement at this stage was about $4.37 \mathrm{~mm}$. After that, the MIW strength increased until the peak load of $38.33 \mathrm{kN}$, corresponding to a displacement of $18.3 \mathrm{~mm}$ (about 2.9 times higher than the cracking displacement). There was a reduction in the strength of about $46 \%$ when it reached $20 \mathrm{kN}$ for a corresponding OOP displacement of $155 \mathrm{~mm}$. The strength reduction was due to the sliding observed on the right side of the panel. The conventional failure occurred for an OOP displacement of $23.23 \mathrm{~mm}$.

Fig. 11b shows the evolution of the top beam vertical displacement along with the OOP force evolution. The main intention was to detect the development of the arching mechanism. From this plot, it is possible to correlate with the force-displacement curve presented in Fig. 11a. It is observed that the top beam vertical displacement increase until the peak load, and after that, it reduced to minimal values, meaning that the arching mechanism reached its limit. The OOP displacement significantly increased until reaching $155 \mathrm{~mm}$ with a residual strength of $16.09 \mathrm{kN}$ (about 59\% lower than $\mathrm{F}_{\mathrm{OOP} \text {, max }}$ ). This residual strength capacity is due to the portion wall that did not collapse. The test stopped at this stage for safety reasons and to protect some of the instruments and 
Out-of-plane drift at control node (\%)

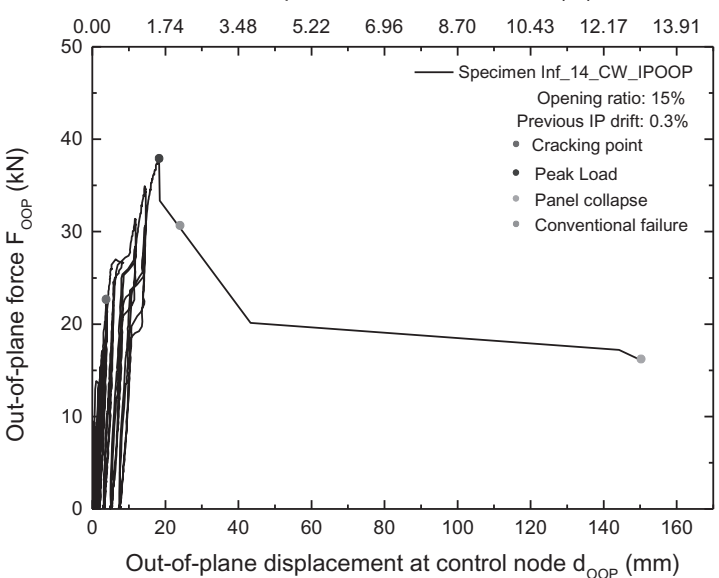

a)

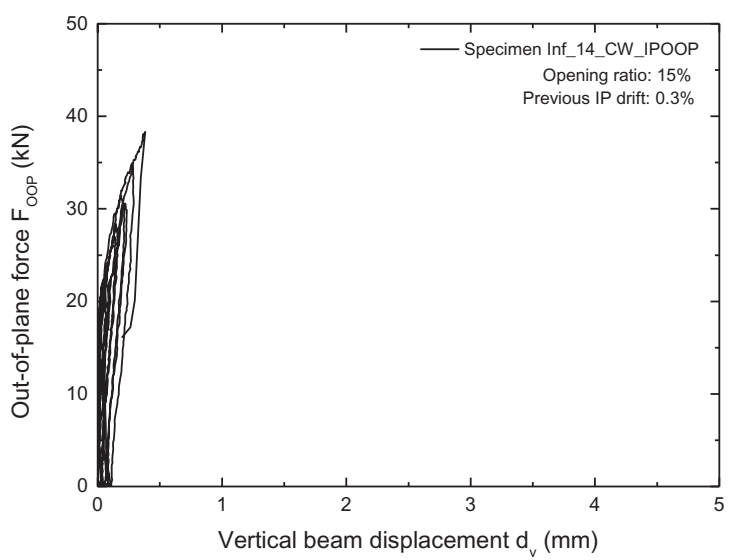

b)

Fig. 13. Specimen Inf_15_CW_OOP - OOP test: (a) Force-displacement curve; and (b) force - vertical beam displacement.

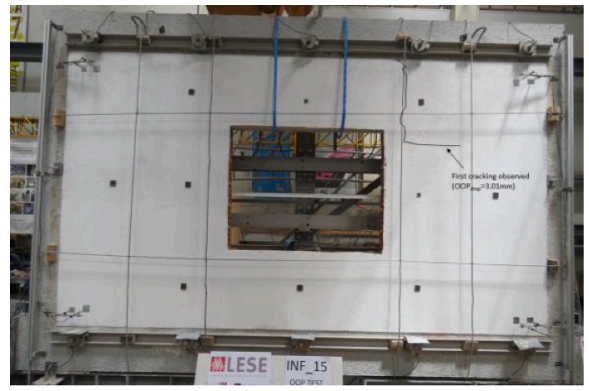

a)

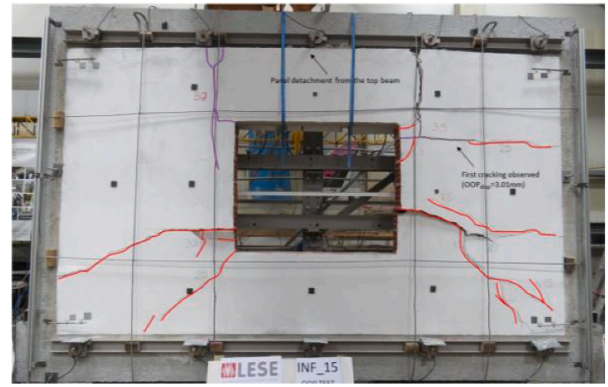

c)

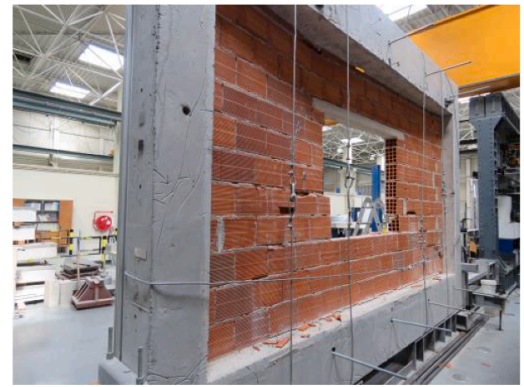

e)

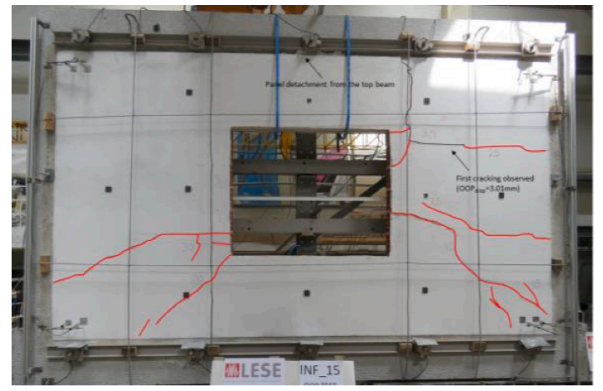

b)

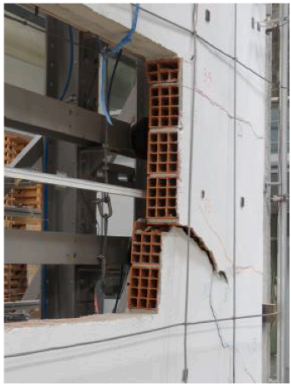

d)

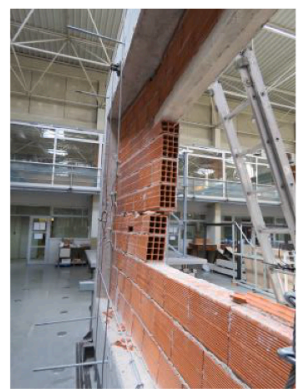

f)

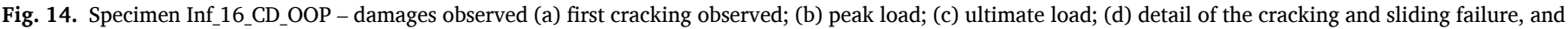
(e) right view. 


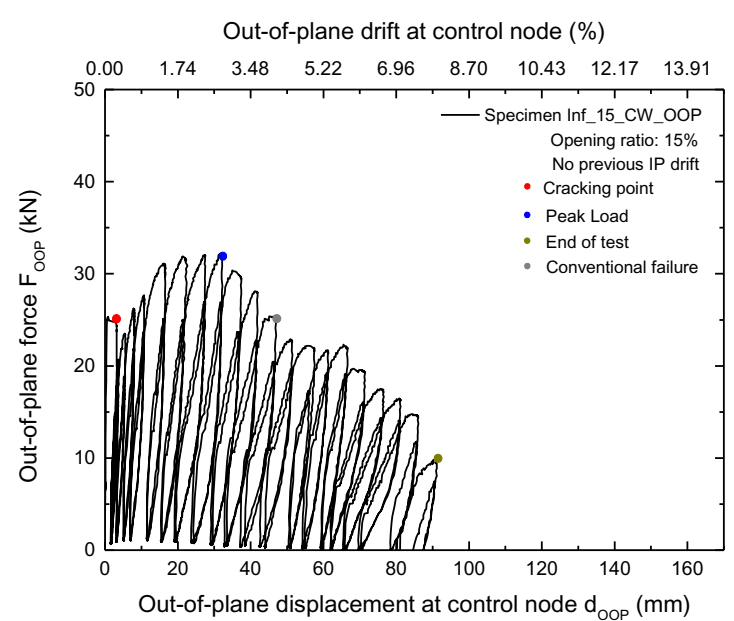

a)

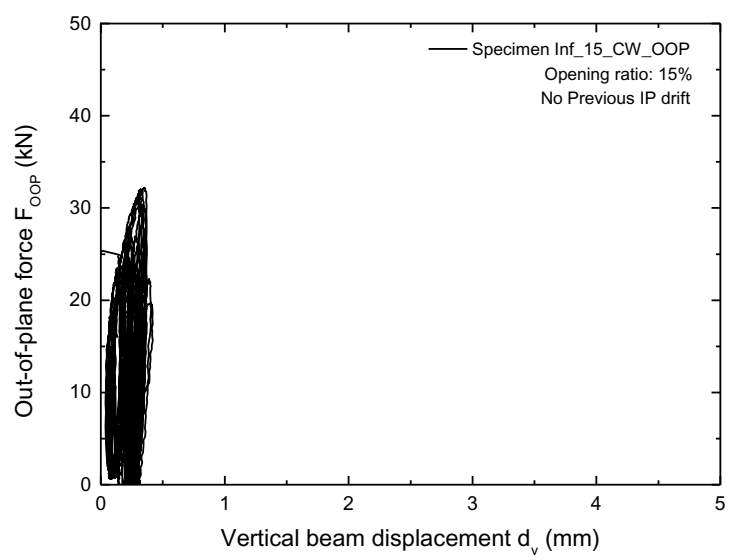

b)

Fig. 15. Specimen Inf_16_CD_OOP - OOP test: (a) Force-displacement curve; and (b) force - vertical beam displacement.

equipment.

\subsection{Out-of-plane test without prior damage}

The Inf_15_CW_OOP test was performed only in the out-of-plane direction without considering any previous damage induce by the in-plane loads. The geometry of the wall and opening is equal do the one presented in the last section. The damage evolution of the specimen Inf_15_CW_OOP is illustrated in Fig. 12. For an OOP displacement of $2.99 \mathrm{~mm}$, the first cracking consisted of one L-shape crack located in the second quadrant of the MIW, as shown in Fig. 12a. Diagonal cracks emerged from the opening bottom corners to the MIW bottom corner. In parallel, the extension of the first cracks occurred, as shown in Fig. 12b. At the peak load, the panel detachment from the top beam was visible. This test was not performed until reaching the MIW collapse. Due to the high deformation and wall instability, it was decided to stop the test protecting the instrumentation and equipment. Fig. 12c shows the observed damages at the ultimate stage. It is visible that the cracking pattern is quite similar to the peak load one. Nonetheless, some differences can be noticed, namely: (i) vertical crack at the top to the left side of the opening; (ii) sliding of the panel along with the diagonal cracks in both sides of the MIW (detailed in Fig. 12d), and (iii) larger cracking thickness of the L-shape. The back view of the damaged MIW is presented in Fig. 12e and f, from which it becomes more evident the panel OOP deformation, the detachment from the top beam and the sliding of the panel.

Fig. 13a shows the force-displacement curve, from which it is possible to extract the initial stiffness of $37.42 \mathrm{kN} / \mathrm{mm}$. There was a quick increase of the force until $24.69 \mathrm{kN}$ in which occurred the first cracking, for a corresponding $2.99 \mathrm{~mm}$. Then, the OOP strength increased until $32.20 \mathrm{kN}$ (1.30 times higher than that of $\left.\mathrm{F}_{\mathrm{OOP}, \text {,rack }}\right)$ for an

Table 3

Comparative analysis: experimental matrix.

\begin{tabular}{llll}
\hline Specimens & Opening & $\begin{array}{l}\text { Previous IP } \\
\text { damage }\end{array}$ & Note \\
\hline Inf_08 & No & No & Reference specimen \\
Inf_11 & No & Yes $(0.3 \%)$ & $\begin{array}{l}\text { Reference specimen } \\
\text { Comparison with }\end{array}$ \\
Inf_14_CW_IPOOP & Yes (central & Yes $(0.3 \%)$ & Inf_11 \\
& window) & Comparison with \\
Inf_15_CW_OOP & Yes (central & No & Inf_08 \\
& window) & & Comparison with \\
Inf_16_CD_OOP & Yes (central door) & No & Inf_08 \\
\hline
\end{tabular}

OOP displacement of $31.5 \mathrm{~mm}$. A progressive reduction of the OOP strength followed the peak load stage, with slight strength reductions for each target displacement. The test stopped for a displacement equal to $90.6 \mathrm{~mm}$ with a residual capacity of $9.76 \mathrm{kN}$ (about $-70 \%$ than $\mathrm{F}_{\mathrm{OOP}}$, $\max$ ). The conventional failure occurred for a displacement of $45.66 \mathrm{~mm}$.

Regarding the arch mechanism development, based on the evolution of the vertical top beam displacement, shown in Fig. 13b, it is possible to observe that the reason behind the fact that this MIW with a central window did not collapse was the arching mechanism development.

\subsection{Specimen Inf_16_CD_OOP (Pure OOP test w/o prior damage)}

The test of the specimen Inf_16_CD_OOP was performed only in the out-of-plane direction without considering any previous damage induce by the in-plane loads. The geometry of the wall is similar to the earlier tests; however, the opening arrangement represents a door. The damage observed in the specimen Inf_16_CD_OOP are shown in Fig. 14, representing three different stages (first cracking, peak load and collapse). The early cracking occurred for an OOP displacement of $1.45 \mathrm{~mm}$. Two horizontal and symmetric cracks were visible at the panel middleheight, as shown in Fig. 14a. The panel detached from the top beam, which caused the vertical cracks that emerged at the top of the opening.

In the same way, a diagonal one in the left side of the MIW, as shown in Fig. 14b. For an OOP displacement of $39.33 \mathrm{~mm}$, the panel collapsed and split into several portions. Different failure mechanisms were observed in the left and right side of the panel. The block comprised by the left span plus the span located upper than the opening behaved differently than the right side span of the wall, namely: (i) the left side of the panel behaved as a unidirectional panel with top and bottom restraint. The flexure occurred in turn of the horizontal crack; (ii) the right span of the wall detached from the frame along with the sliding failure (stairs shape). Details from the collapse are presented in Fig. 14c-e.

The force-displacement curve is plotted in Fig. 15a, from which an initial stiffness of $29.49 \mathrm{kN} / \mathrm{mm}$ is noticed. The OOP strength increased until $27.11 \mathrm{kN}$, where it occurred the first macro-cracking. Then, the panel strength increased by $20 \%$ to $32.48 \mathrm{kN}$ for an OOP displacement equal to $15.9 \mathrm{~mm}$. After that, there was a reduction of the panel strength by $18 \%$ to $26 \mathrm{kN}$. Suddenly, it occurred the total collapse of the specimen (displacement equal to $36 \mathrm{~mm}$ ). Fig. 15b shows the evolution of the top beam vertical displacement in which it becomes clear that the arching mechanism occurred until the panel collapse. The conventional failure occurred for an OOP displacement of $35.22 \mathrm{~mm}$. 


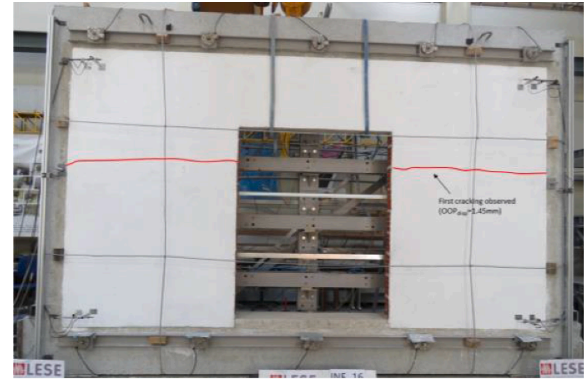

a)

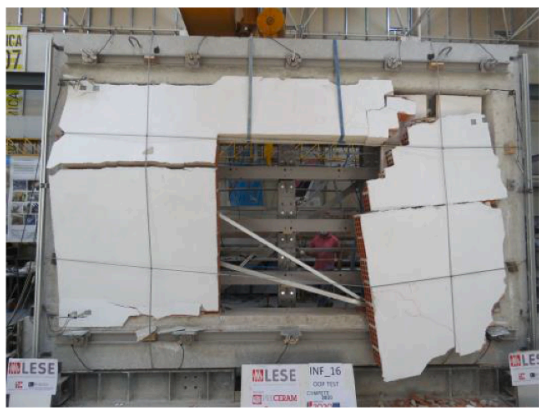

c)

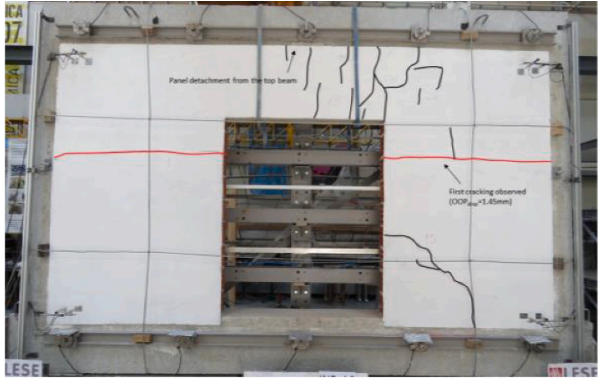

b)

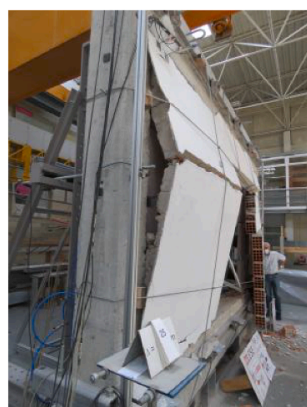

d)

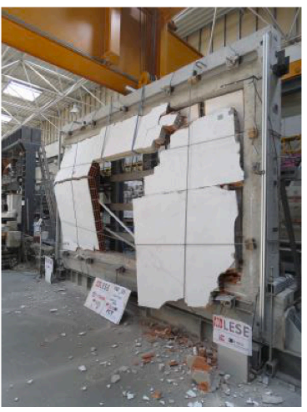

e)

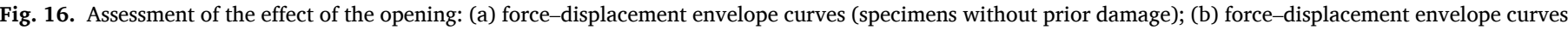
(specimens with previous IP damage); (c) relative stiffness (specimens without prior damage); and (d) relative stiffness (specimens without prior damage).

Table 4

Assessment of the effect of the openings: Comparisons of the results.

\begin{tabular}{|c|c|c|c|c|c|}
\hline \multirow[t]{2}{*}{ Parameters } & \multicolumn{2}{|c|}{$\begin{array}{l}\text { Reference } \\
\text { Specimens without openings }\end{array}$} & \multicolumn{3}{|c|}{ Specimens with openings } \\
\hline & $\begin{array}{l}\text { Inf_08 } \\
\text { (OOP) }\end{array}$ & $\begin{array}{l}\text { Inf_11 } \\
\text { (IP-OOP) }\end{array}$ & Inf_14_CW_IPOOP & Inf_15_CW_OOP & Inf_16_CD_OOP \\
\hline $\mathrm{k}_{\mathrm{OOP}, \mathrm{sec}, \text { ini }}(\mathrm{kN} / \mathrm{mm})$ & 20.32 & 7.97 & 21.38 & 37.42 & 29.49 \\
\hline $\mathrm{F}_{\mathrm{OOP}, \text { crack }}(\mathrm{kN})$ & 22.60 & 23.85 & 23.41 & 24.69 & 27.11 \\
\hline $\mathrm{F}_{\mathrm{OOP}, \max }(\mathrm{kN})$ & 44.15 & 30.72 & 38.33 & 32.20 & 32.48 \\
\hline $\mathrm{F}_{\mathrm{OOP}, \mathrm{conv}}(\mathrm{kN})$ & 35.04 & 24.74 & 30.66 & 25.76 & 25.98 \\
\hline $\mathrm{d}_{\mathrm{OOP}, \text { crack }}(\%)$ & 0.11 & 0.88 & 0.38 & 0.26 & 0.13 \\
\hline $\mathrm{d}_{\mathrm{OOP}, \max }(\%)$ & 2.21 & 4.47 & 1.59 & 2.74 & 1.38 \\
\hline $\mathrm{d}_{\mathrm{OOP}, \text { conv }}(\%)$ & $2.66^{*}$ & 5.76 & 2.02 & 3.97 & 3.06 \\
\hline $\mathrm{d}_{\mathrm{OOP}, \mathrm{ult}}(\%)$ & 2.66 & 8.87 & 13.48 & 7.88 & 3.13 \\
\hline
\end{tabular}

* Note: The specimen Inf_08 collapsed before reaching the conventional rupture stage. Due to this, it was assumed that the conventional rupture corresponds to the ultimate stage of the test.

\section{Comparision of the openings effect and critical analysis}

This work aims to discuss the effect of the openings in the MIW behaviour under OOP loadings since the results available in the literature are scarce. The comparison of the results obtained by MIW with and without openings are essential for supporting this discussion. The specimens without openings, Inf_08 and Inf_11, available in the literature [23] are herein used as reference panels, once they were tested without openings and in similar test conditions (without and with prior IP damage) with the same loading protocol. The details of the comparative analysis herein performed are summarized in Table 3 . The experimental results above described are compared to each other in terms of 
Table 5

Assessment of the effect of the openings: relative comparisons.

\begin{tabular}{|c|c|c|c|}
\hline \multirow[t]{2}{*}{ Parameters } & \multicolumn{2}{|l|}{ Pure OOP tests } & \multirow{2}{*}{$\begin{array}{l}\begin{array}{l}\text { Combined IP + OOP } \\
\text { tests }\end{array} \\
\text { Inf_14_CW_IPOOP/ } \\
\text { Inf11 }\end{array}$} \\
\hline & $\begin{array}{l}\text { Inf_15_CW_OOP/ } \\
\text { Inf_08 }\end{array}$ & $\begin{array}{l}\text { Inf_16_CD_OOP/ } \\
\text { Inf_08 }\end{array}$ & \\
\hline $\mathrm{k}_{\mathrm{OOP}, \mathrm{sec}, \mathrm{ini}}$ & 1.84 & 1.45 & 2.68 \\
\hline $\mathrm{F}_{\mathrm{OOP}, \mathrm{crack}}$ & 1.09 & 1.20 & 0.98 \\
\hline $\mathrm{F}_{\mathrm{OOP}, \max }$ & 0.73 & 0.74 & 1.25 \\
\hline $\mathrm{F}_{\mathrm{OOP}, \mathrm{conv}}$ & 0.74 & 0.75 & 1.24 \\
\hline $\mathrm{d}_{\mathrm{OOP}, \mathrm{crack}}$ & 2.36 & 1.18 & 0.43 \\
\hline $\mathrm{d}_{\mathrm{OOP}, \max }$ & 1.24 & 0.62 & 0.36 \\
\hline $\mathrm{d}_{\mathrm{OOP}, \text { conv }}$ & 1.49 & 1.15 & 0.35 \\
\hline $\mathrm{d}_{\mathrm{OOP}, \mathrm{ult}}$ & 2.96 & 1.18 & 1.52 \\
\hline
\end{tabular}

OOP force-displacement envelopes, stiffness degradation, peak load, ratio peak load/panel mass, and energy dissipation.

\subsection{Force-displacement envelope curves}

Fig. 16a and b presents a comparison between the envelope $\mathrm{F}_{\mathrm{OOP}^{-}}$ $\mathrm{d}_{\mathrm{OOP}}$ curves of the specimens without prior damage (Inf_08, Inf_15_CW_OOP and Inf_16_CD_OOP) and with previous IP damage (Inf_11 and Inf_14_CW_IPOOP). Similarly, the relative secant stiffness evolution is shown in Fig. 16c and d, respectively. Finally, Tables 4 and 5 summarise the main results, as commented in the following remarks. Parameters such as the initial stiffness, cracking force and corresponding displacement $\left(\mathrm{F}_{\mathrm{OOP}, \text { crack }}\right.$ and $\mathrm{d}_{\mathrm{OOP}, \text { crack }}$ ), peak load and corresponding displacement $\left(\mathrm{F}_{\mathrm{OOP}, \max }\right.$ and $\left.\mathrm{d}_{\mathrm{OOP}, \max }\right)$, and conventional failure load and corresponding displacement ( $\mathrm{F}_{\mathrm{OOP}, \mathrm{conv}}$ and $\mathrm{d}_{\mathrm{OOP} \text {,conv }}$ ) will be analyzed and discussed in this subsection.

The initial secant stiffness, $\mathrm{k}_{\mathrm{OOP}}$,sec,ini, was calculated for each specimen. Specimen Inf_15_CW_OOP reached the maximum value with $37.42 \mathrm{kN} / \mathrm{mm}$, and the lowest one was achieved by the reference specimen Inf_11 with $7.97 \mathrm{kN} / \mathrm{mm} \quad(79 \%$ lower $)$. The specimen Inf_14_CW_IPOOP reached an initial stiffness 2.68 times higher than Inf_11, which can be explained by the slight damage introduced by the IP test of the wall Inf_14_CW_IPOOP when compared with the damages observed in the test of Inf 11 . Also, it is important to mention that the RC lintel of the specimen Inf_14_CW_IPOOP could also have contributed to this difference. The specimen Inf_08 reached an initial stiffness of about $46 \%$ and $22 \%$ lower than Inf_15_CW_OOP and Inf_16_CD_OOP. The RC lintel can also justify this difference. However, a detailed finite element analysis needs to be carried out to address this issue.

Regarding the comparison between the panels Inf_14_CW_IPOOP and Inf_15_CW_OOP, it is possible to observe that the prior damage reduced the initial stiffness by about $43 \%$. On the other hand, it can be noticed that the increase of the opening area reduced the initial stiffness by about $22 \%$.

It is possible to observe that, regarding the force corresponding to the first cracking development, the panel Inf_14_CW_IPOOP reached the highest value among the panels with openings with force equal to $23.41 \mathrm{kN}$. The cracking strength of Inf_14_CW_IPOOP is similar to the one achieved by the reference specimen Inf_11. By comparing the specimen Inf_08 with the specimens Inf_15_CW_OOP and Inf_16_CD_OOP, it can be observed that the cracking force was $9 \%$ and $20 \%$ lower, respectively. Concerning the effect of the opening area, it can be stated that the specimen Inf_16_CD_OOP reached a cracking strength $9 \%$ higher than Inf_15_CW_OOP.

Regarding the OOP drift for which occurred the first macro-cracking $\left(\mathrm{d}_{\mathrm{OOP}, \text { crack }}\right)$, it can be noticed that: (i) Inf 11 reached the maximum value with $0.88 \%$ and the lowest by Inf 08 with $0.11 \%$; (ii) the $\mathrm{d}_{\mathrm{OOP} \text {, crack }}$ of the specimens Inf_15_CW_OOP and Inf_16_CD_OOP was $136 \%$ and $18 \%$ higher than that of Inf_08; (iii) Inf_14_CW_IPOOP got the first crack for a $\mathrm{d}_{\mathrm{OOP}, \text { crack }} 67 \%$ lower than Inf 11 ; (iv) the increment of the opening area reduced the $\mathrm{d}_{\mathrm{OOP} \text {,crack }}$ about $50 \%$.

The analysis of the peak load stage showed results variability again since it was found that some of the specimens with openings reached peak load values higher than those achieved by the reference ones. The results of the panels without prior damage showed that the openings reduced the maximum OOP strength capacity. The specimen Inf_08 reached a maximum of $44.15 \mathrm{kN}$, about $30 \%$ higher than Inf_15_CW_OOP and Inf_16_CD_OOP $(32.20 \mathrm{kN}$ and $32.48 \mathrm{kN}$, respectively). The peak load of Inf_14_CW_IPOOP was 1.25 times higher than Inf_11. The arching mechanism could have had an essential role in this result since it could have increased the panel Inf_14_CW_IPOOP strength capacity. On the other hand, from the global force-displacement curves, the specimen Inf 11 did not collapse for lower displacement demands, which means that the arching mechanism acted importantly to guarantee the OOP resistance of the panel. Experimental variability can justify this result, and additional comparative studies of MIW with openings subjected to prior IP drift demands are needed to perform shortly.

The OOP displacement at the peak load stage $\left(\mathrm{d}_{\mathrm{OOP}, \max }\right)$ again found some results variation. For example, the wall Inf_08 reached a drift value $20 \%$ lower than that of Inf_15_CW_OOP and $60 \%$ higher than Inf_16_CD_OOP. On the other hand, the specimen Inf_11 achieved a $d_{O O P}$,

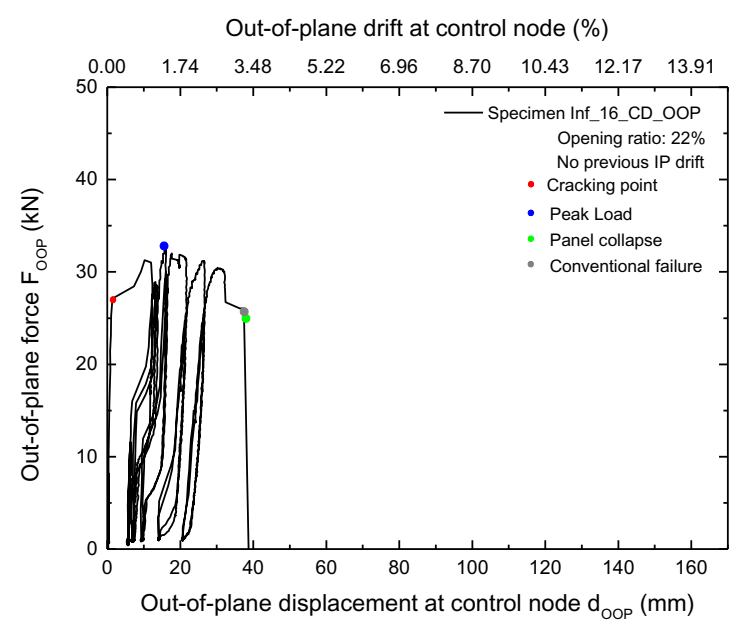

a)

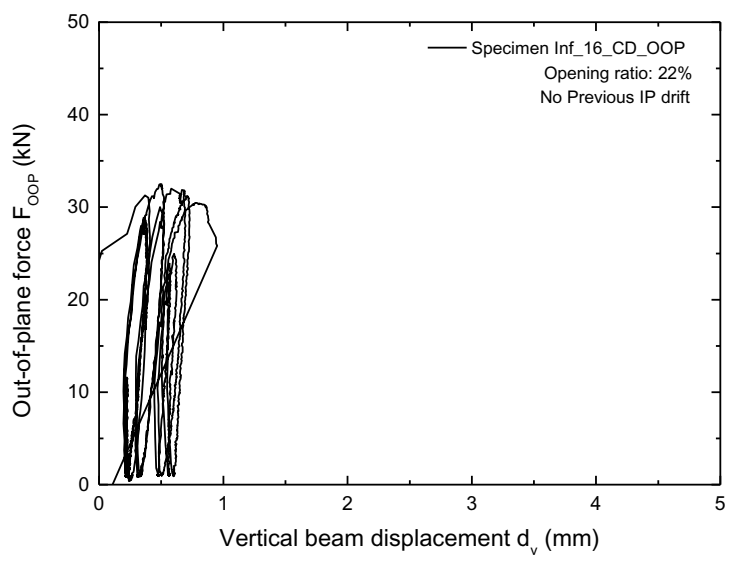

b)

Fig. 17. Assessment of the effect of the openings: (a) OOP drift $\mathrm{d}_{\mathrm{OOP}}$ (specimens without prior damage); (b) OOP drift $\mathrm{d}_{\mathrm{OOP}}$ (models with previous damage); (c) OOP strength $\mathrm{F}_{\mathrm{OOP}}$ (specimens without prior damage) and (d) OOP strength $\mathrm{F}_{\mathrm{OOP}}$ (specimens with prior damage). 


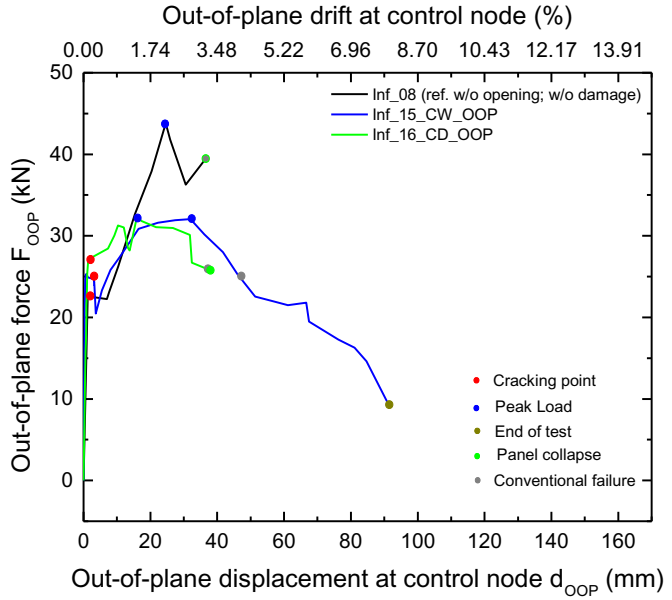

a)

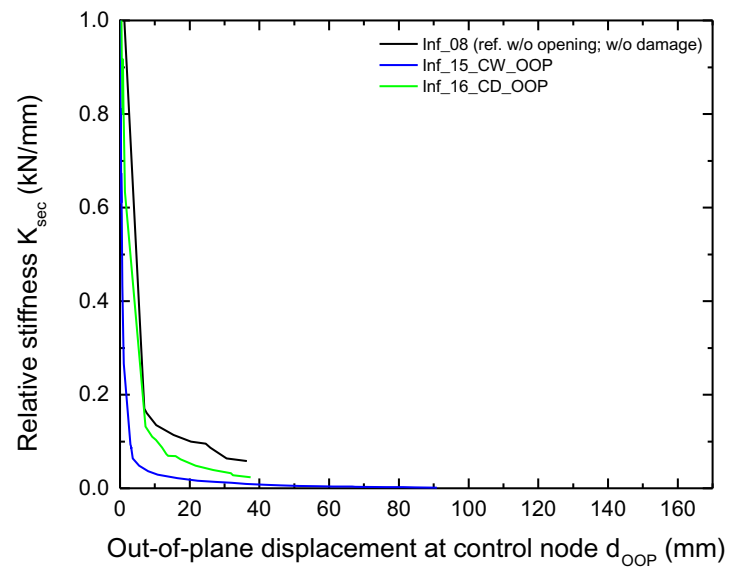

c)

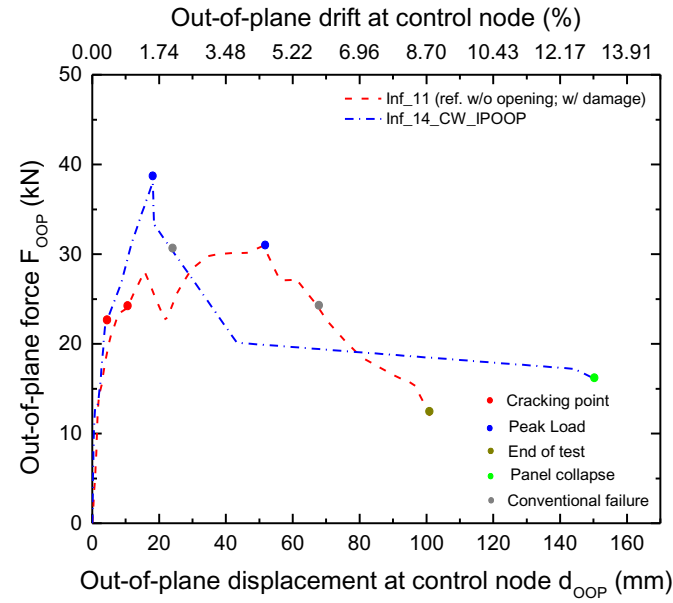

b)

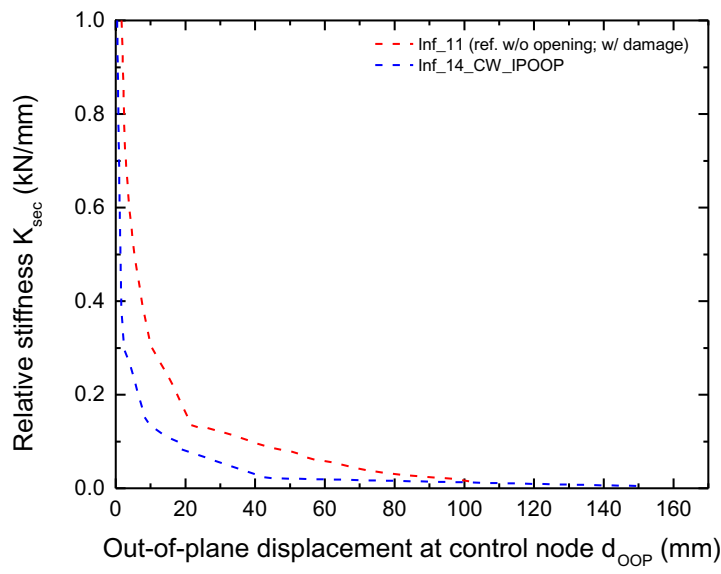

d)

Fig. 18. Assessment of the effect of the openings: Dissipated energy per cycle: (e) Inf_14_CD_OOP.

$\max 2.81$ times higher than Inf_14_CW_IPOOP, indicating that the openings can reduce the $\mathrm{d}_{\mathrm{OOP} \text {,max. }}$ Finally, the increase of the opening area reduced the $\mathrm{d}_{\mathrm{OOP} \text {,max }}$ by about $49 \%$.

To finish the analysis of the force-displacement curves, it remains the discussion of the displacement for the conventional failure. This stage corresponds to $80 \%$ of the peak load at the post-peak phase $\left(\mathrm{F}_{\mathrm{OOP}}\right.$, conv and $\mathrm{d}_{\mathrm{OOP} \text {,conv }}$ ). Concerning the pure OOP tests, it was observed that the conventional failure occurred for higher OOP displacements in the walls with openings. Inf_15_CW_OOP reached a d $\mathrm{OOOP}_{\text {,conv }} 49 \%$ higher than that of Inf_08. The wall with a door (Inf_16_CD_OOP) achieved a $\mathrm{d}_{\mathrm{OOP}, \text { conv }} 15 \%$ times higher than the reference specimen. It can also be noticed that the increment of the opening area reduced the $d_{O O P}$,conv about $23 \%$. The specimen Inf_14_CW_IPOOP reached a d $\mathrm{d}_{\text {OOP,conv }} 65 \%$ lower than the one obtained by Inf_11.

Fig. 17a and b show the comparison between the drift reached in each stage (cracking, peak and conventional failure) for the group of specimens without and with prior damage. It becomes more evident that, in what concern to the models without previous IP damage, the specimen Inf_15_CW_OOP reached the highest value in all of the stages. On the other hand, the specimens Inf_08 and Inf_16_CD_OOP presented similar drift values at the first cracking. The group with previous IP damage shows some variations in each step, namely the specimen Inf_14_CW_IPOOP reached lower $\mathrm{d}_{\mathrm{OOP}, \max }$ and $\mathrm{d}_{\mathrm{OOP}, \text { conv }}$.

Similar observations can be drawn in Fig. 17c and d where it is plotted the force reached by the group without and with previous IP damage in each stage, respectively. The openings seem to reduce the walls strength capacity. At the first cracking stage, the openings did not affect the panel strength capacity. From the analysis of the walls with prior damage, it can be noticed that the Inf_14_CW_IPOOP always reached the highest strength capacity. This not expected result can be related to experimental variability. Further investigations should be developed to clarify this issue.

To conclude the analysis of the force-displacement curves response parameters, some considerations can be drawn regarding the relative stiffness or stiffness degradation plotted in Fig. 16c and d. It is possible to observe that the panels with openings reached higher stiffness degradation for the same OOP displacement demand. It can also be noticed that the increase of the opening area increased the panel stiffness degradation.

The force-displacement hysteretic curves are plotted in Fig. 20, where it will be possible to assess the following issues: (i) effect of the opening without IP previous damage (Fig. 20a and b); (ii) effect of the opening with IP previous damage (Fig. 20c) and (iii) effect of the opening area (Fig. 20d).

To conclude the analysis of the openings' impact, it is presented in Fig. 21a the maximum peak load reached by all the specimens. It is possible to observe that, without previous damage, the openings reduced the maximum strength about $30 \%$. As previously mentioned, the same was not observed in the specimens with previous damage, where it was found a peak strength $25 \%$ higher by the wall with a central 


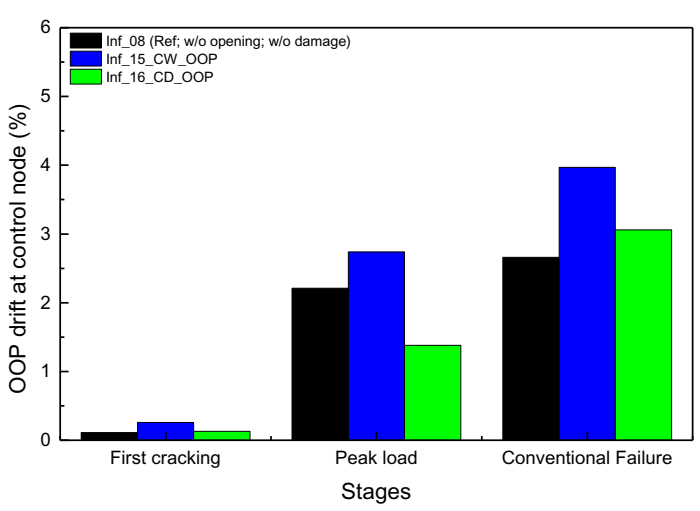

a)

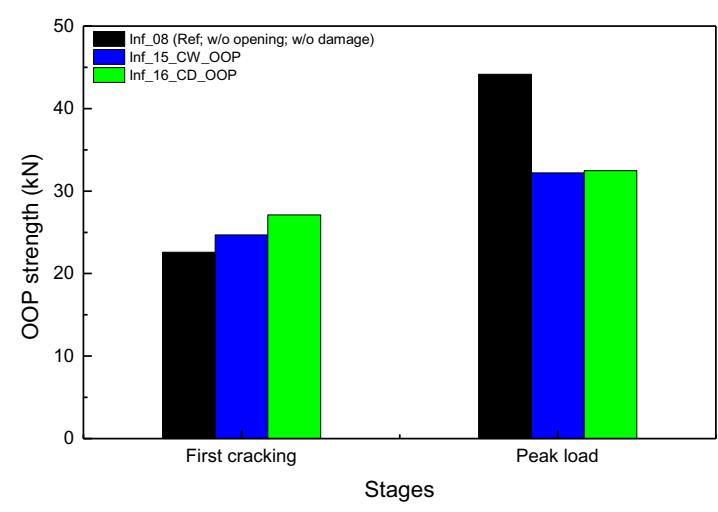

c)

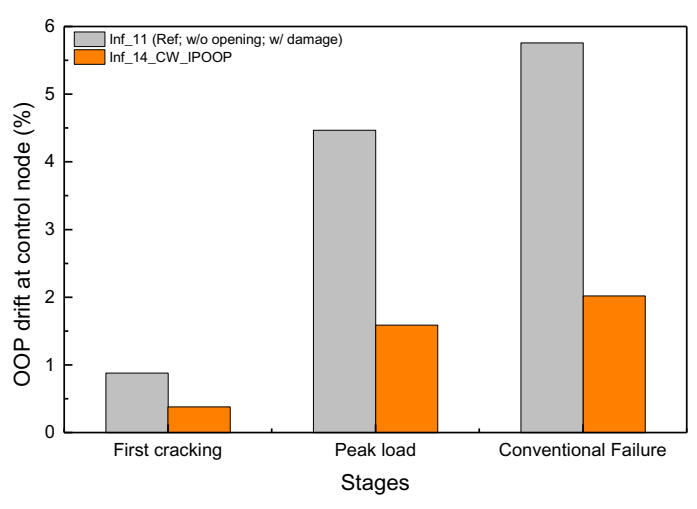

b)

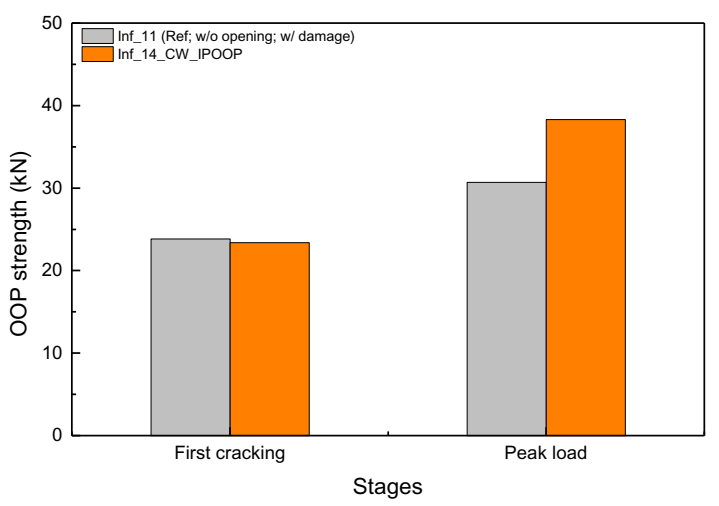

d)

Fig. 19. Assessment of effect of the openings: Cumulative energy dissipation.

window. It is plotted in Fig. 21b the ratio between the maximum peak load and each panel mass to compute the equivalent seismic demand. From the results, it is possible to observe that Inf_16_CD_OOP reached a ratio of $0.37,8 \%$ and $37 \%$ higher than Inf_08 and Inf_15_CW_OOP. Again, the ratio of the panel Inf_14_CW_IPOOP was 20\% higher than the one reached by Inf_11. From this, it can be concluded that the openings increased the expected seismic demand necessary to collapse due to the respective panel mass reduction.

\subsection{Cumulative energy dissipation}

The energy dissipated in each loading-unloading (half-cycle) and the cumulative energy dissipation throughout the whole test history were calculated and plotted in Fig. 18. From the plots of the energy dissipated in each cycle, some differences can be pointed: (i) some peaks can be identified in the panels with the openings that corresponded to sudden large displacements reached by the panels when occurred sliding between the wall and the top beam or development of any cracking; and (ii) in average, the panels with openings dissipated lower energy per cycle, except the specimen Inf_16_CD_OOP; (iii) all the specimens dissipated higher energy at the first half-cycle than the second one $(30 \%$ for the panels without openings and $40 \%$ for the panels with openings).

The cumulative energy dissipation was computed and is plotted in Fig. 19. From that, it can be noticed that the total cumulative energy dissipation reached by the specimen Inf_08, Inf_11, Inf_14_CW_IPOOP, Inf_15_CW_OOP and Inf_16_CD_OOP were, respectively, 1.9, 3.9, 1.2, 2 and $1.3 \mathrm{kNm}$.

The cumulative energy dissipation evolution is plotted in Fig. 19, from which it is possible to observe that, for smaller OOP displacement demand, the panels Inf_14_CW_IPOOP and Inf_15_CW_OOP dissipated highers levels of energy (3-4 times higher) than the remaining specimens. For larger OOP displacements it can be observed that the increment of energy dissipation is more pronounced for specimens without openings.

From the comparison between the panels without previous IP damage, it can be observed that for an OOP displacement around $30 \mathrm{~mm}$, the specimens Inf_08 reached a cumulative energy dissipation 5\% and 55\% higher than that of Inf_16_CD_OOP and Inf_15_CW_OOP, respectively. For the same displacement, the specimen Inf 11 reached a cumulative energy dissipation similar to the one reached by Inf_14_CW_IPOOP, which means that the opening did not affect this parameter. Finally, from the analysis of the total cumulative energy dissipation, it is clear the efficiency of the openings, since it was reached by all of them equal or lower cumulative energy dissipation than the ones reached by the panels without the openings. For example, the specimen Inf_08 dissipated similar energy dissipation than the specimen Inf_15_CW_OOP and $45 \%$ higher than Inf_16_CD_OOP. Regarding the wall Inf_11, it dissipated 3.9 times higher energy dissipation when compared with Inf_14_CW_IPOOP.

\section{Final remarks}

Most of the studies available in the literature concerning the MIW OOP behaviour do not cover the openings' effect. However, the buildings façades are comprised of MIW with different types of openings, which needed proper characterization of their seismic behaviour. Based on this motivation, this manuscript's primary goal was to study the effect of the openings and their areas in the MIW OOP behaviour. For this, an experimental campaign was carried out comprising three full-scale specimens. Two of them were walls with central windows, one with 


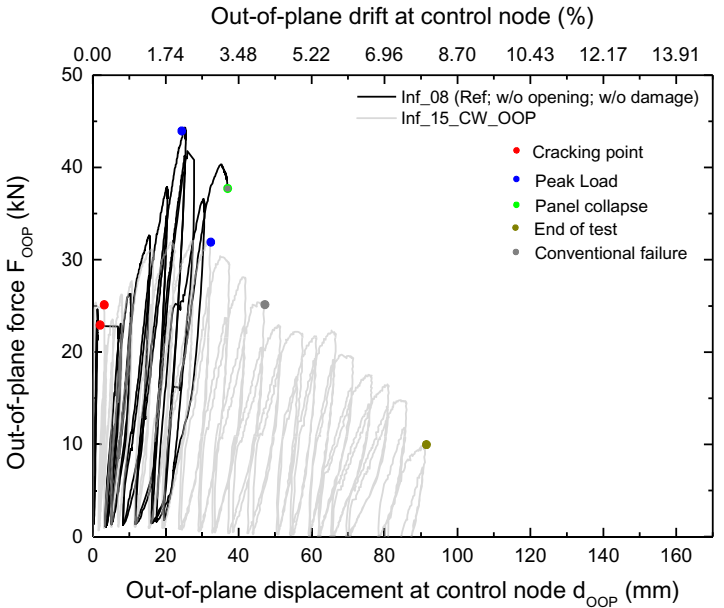

a)

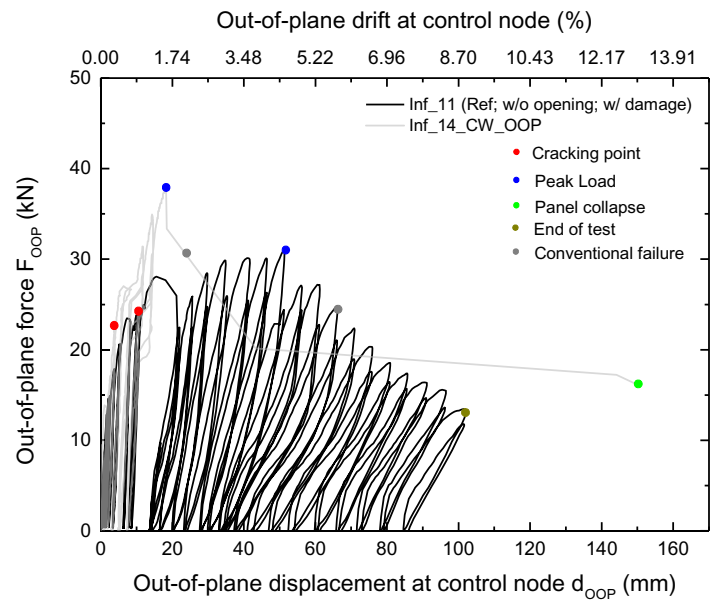

c)

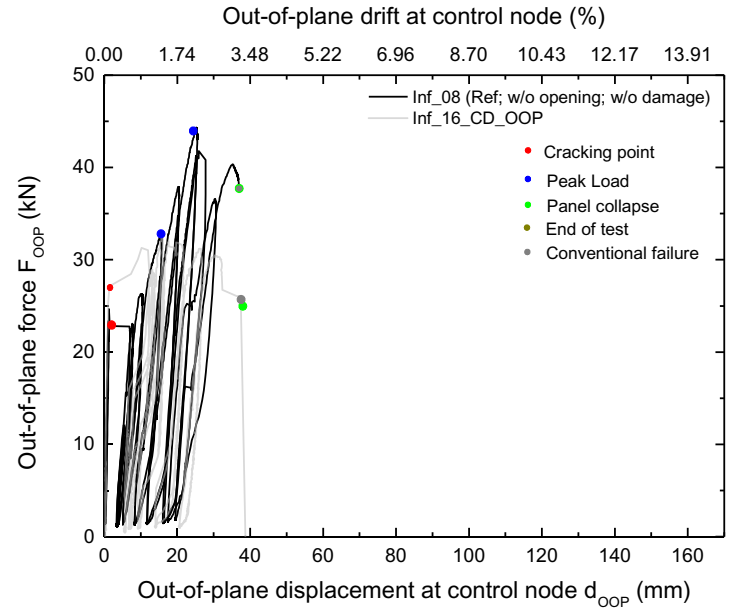

b)

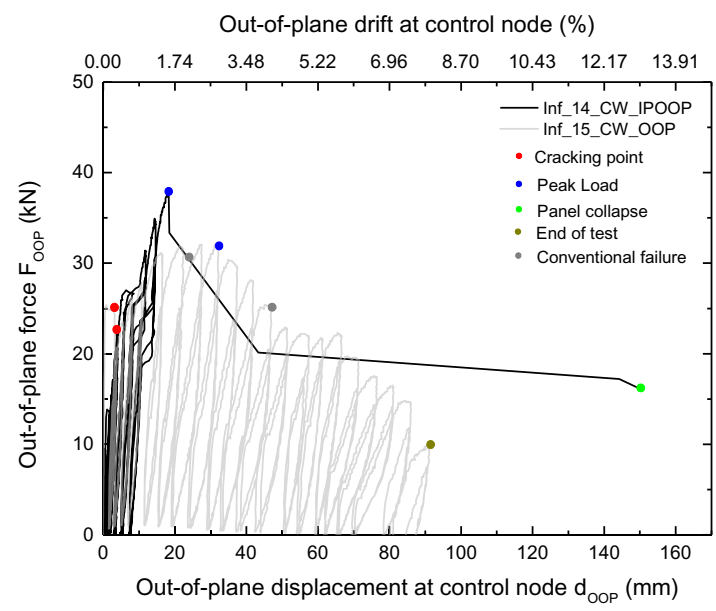

d)

Fig. 20. Analysis of the openings effect: force-displacement curves: (a) Inf_08 vs Inf_15_CW_OOP; (b) Inf_08 vs Inf_16_CD_OOP; (c) Inf_11 vs Inf_14_CW_IPOOP; and (d) Inf_14_CW_IPOOP vs Inf_15_CW_OOP.

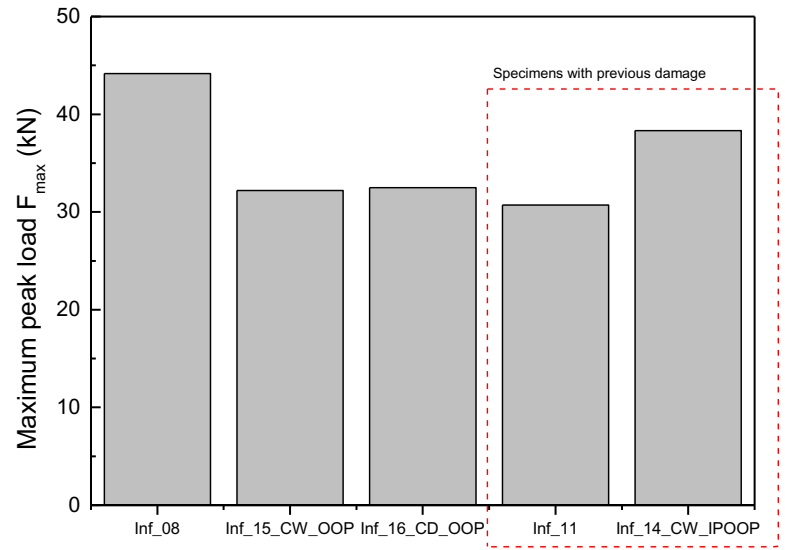

a)

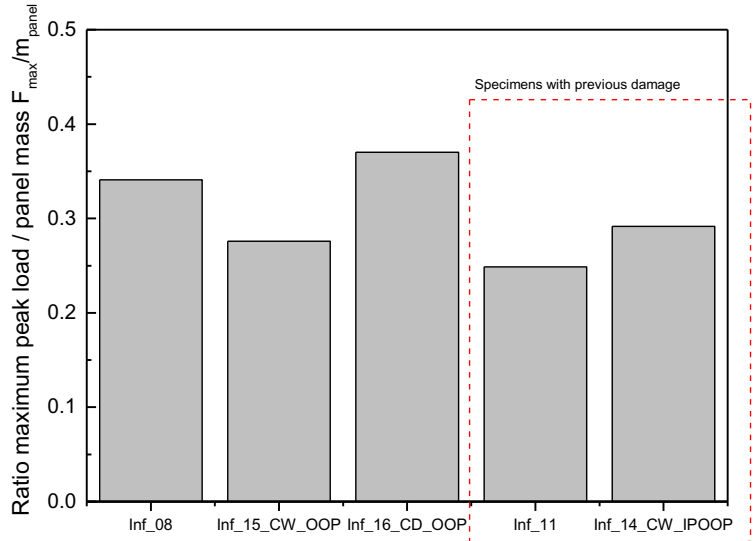

b)

Fig. 21. Analysis of the opening's effect: (a) peak load and (b) ratio between peak load and panel mass. 
and one without prior IP damage. The third wall was built with a central door, whose area was $46 \%$ higher than the window area. Two reference specimens, without openings, from previous research work, were used as reference specimens to conclude the openings' effect. All the tests have been performed by imposing a half-cyclic (loading-unloadingreloading) history of displacements in the out of plane (OOP) direction employing a uniform distributed load provided by small pneumatic jacks. From the testing campaign, the following conclusions can be drawn:

- The openings modified the walls' OOP response. The failure mechanisms were characterized by a combination of sliding failure plus the panel's detachment from the top beam. The collapse occurred without prior reduction of the OOP strength, similarly to what was observed in the walls without openings. It was observed in all the tests that the arching mechanism plays a crucial role in the walls;

- The initial stiffness of the walls increased with the openings due to the RC lintels. However, further investigation needs to be performed concerning the RC lintel's effect on infill walls' OOP response. It was also found a reduction of the initial stiffness with the increment of the opening area;

- The initial stiffness increment impacted directly in an increase of force and displacement corresponding to the first macro-cracking development. The cracking force increased between $9 \%$ and $20 \%$ due to the openings;

- The openings reduced the specimens' peak strength capacity without prior IP damage about 30\%; however, the same was not observed in the wall with initial IP damage where it was found an increment of the strength capacity up to $25 \%$;

- The collapse of the panel with a central door occurred for similar OOP displacements demands of those observed in the wall with a central window. It was found lower residual strength of the walls due to the openings;

- The conventional failure occurred for $20-50 \%$ larger displacements due to the openings for specimens without prior damage. For the group with previous damage, the conventional collapse occurred for smaller displacements;

- The openings reduced the panel energy dissipation capacity between 40 and $70 \%$. The increment of the opening area also reduced the dissipation capacity of the panel.

Future complementary studies should be carried out to validate the tests herein presented and address other typologies such as excentric openings (window or door), different openings ratio, and different loading protocols. A future testing campaign comprising IP plus OOP test sequences are planned to perform in walls (with and without openings) for different IP drift levels. Future finite element studies would also help clarify the RC lintel's effect in walls with different openings' typologies. The results will allow reinforcing the calibration of numerical models to simulate the behaviour of MIW with openings.

\section{CRediT authorship contribution statement}

André Furtado: Conceptualization, Methodology, Formal analysis, Investigation, Writing - original draft. António Arêde: Conceptualization, Methodology, Investigation, Validation, Investigation, Writing review \& editing, Supervision, Project administration. Hugo Rodrigues: Conceptualization, Methodology, Formal analysis, Investigation, Writing - review \& editing, Supervision. Humberto Varum: Conceptualization, Methodology, Investigation, Validation, Investigation, Writing - review \& editing, Supervision, Project administration.

\section{Declaration of Competing Interest}

The authors declare that they have no known competing financial interests or personal relationships that could have appeared to influence the work reported in this paper.

\section{Acknowledgements}

This work was financially supported by: Base Funding - UIDB/ 04708/2020 and Programmatic Funding - UIDP/04708/2020 of the CONSTRUCT - Instituto de I\&D em Estruturas e Construções - funded by national funds through the FCT/MCTES (PIDDAC). This work was also supported by the Foundation for Science and Technology (FCT) - Aveiro Research Centre for Risks and Sustainability in Construction (RISCO), Universidade de Aveiro, Portugal [FCT/UIDB/ECI/04450/2020].

The authors would also like to acknowledge the Laboratory of Earthquake and Structural Engineering (LESE) technicians, Mr. Guilherme Nogueira and Mr. Nuno Pinto, for supporting the experimental activity reported in this research work. The authors would also like to express a special acknowledgement to the reviewers for their valuable suggestions that increased the manuscript quality.

\section{References}

[1] Cavaleri L, Di Trapani F. Cyclic response of masonry infilled RC frames: Experimental results and simplified modeling. Soil Dyn Earthq Eng 2014;65: 224-42.

[2] Luca F, Verderame GM, Gómez-Martínez F, Pérez-García A. The structural role played by masonry infills on RC building performances after the 2011 Lorca, Spain, earthquake. Bull Earthq Eng 2014;12.

[3] Hermanns L, Fraile A, Alarcón E, Álvarez R. Performance of buildings with masonry infill walls during 2011 Lorca earthquake. Bull Earthq Eng 2014;12: 1977-97.

[4] Furtado A, Rodrigues H, Arêde A, Varum H. Influence of the in plane and out-ofplane masonry infill walls' interaction in the structural response of RC buildings. Procedia Eng 2015;114:722-9.

[5] Masi A, et al. Seismic response of RC buildings during the Mw 6.0 August 24, 2016 Central Italy earthquake: the Amatrice case study. Bull Earthq Eng 2019;17(10): $5631-54$

[6] Angel R, Abrams D, Shapiro D, Uzarski J, Webster M. Behavior of reinforced concrete frames, with masonry infills. Civil Engineering Studies, Reserach Series No. 589, UILU-ENG. USA: Department of Civil Engineering, University of Ilinois; 1994. p. 94-2005.

[7] Dafnis A, Kolsch H, Reimerdes H-G. Arching in masonry walls subjected to earthquake motions. J Struct Eng 2002;128(2):153-9.

[8] Sepasdar R. Experimental investigation on the out-of-plane behaviour of concrete masonry infilled RC frames (MSc Thesis). Nova Scotia: Dalhousie University Halifax; 2017.

[9] Wang C. Experimental Investigation on the Out-Of-Plane behaviour of concrete masonry infilled frame (MSc Thesis). Nova Scotia: Dalhousie University Halifax; 2020.

[10] Ricci P, Di Domenico M, Verderame GM. Experimental investigation of the influence of slenderness ratio and of the in-plane/out-of-plane interaction on the out-of-plane strength of URM infill walls. Constr Build Mater 2018;191:507-22.

[11] Nasiri E, Liu Y. The out-of-plane behaviour of concrete masonry infills bounded by reinforced concrete frames. Eng Struct 2019;184:406-20.

[12] Flanagan RD, Bennett RM. Bidirectional behavior of structural clay tile infilled frames. J Struct Eng 1999;125(3):236-44.

[13] Milanesi R, Magenes G, Morandi P, Hak S. "The interaction between in-plane and out-of-plane seismic response of modern strong masonry infills. 17th International Brick/Block Masonry Conference (17thIB2MaC 2020), Krakow, Poland. 2020.

[14] Komaraneni S, Rai DC, Singhal V. Seismic behavior of framed masonry panels with prior damage when subjected to out-of-plane loading. Earthq Spectra 2011;27(4): 1077-103.

[15] Mohyeddin A, Goldsworthy HM, Gad EF. FE modelling of RC frames with masonry infill panels under in-plane and out-of-plane loading. Eng Struct 2013;51:73-87.

[16] De Risi MT, Di Domenico M, Ricci P, Verderame GM, Manfredi G. Experimental investigation on the influence of the aspect ratio on the in-plane/out-of-plane interaction for masonry infills in RC frames. Eng Struct 2019;189:523-40.

[17] Akhoundi F, Vasconcelos G, Lourenço P. Experimental out-of-plane behavior of brick masonry infilled frames. Int J Architect Heritage 2018;14(2):221-37.

[18] Furtado A, Teresa de Risi M. Recent findings and open issues concerning the seismic behaviour of masonry infill walls in RC buildings. Adv Civil Eng 2020; 2020:9261716.

[19] Dawe JL, Seah CK. Out-of-plane resistance of concrete masonry infilled panels. Can J Civ Eng 1989;16.

[20] Anić F, Penava D, Abrahamczyk L, Sarhosis V. A review of experimental and analytical studies on the out-of-plane behaviour of masonry infilled frames. Bull Earthq Eng 2020;18(5):2191-246.

[21] Liberatore L, AlShawa O, Marson C, Pasca M, Sorrentino L. Out-of-plane capacity equations for masonry infill walls accounting for openings and boundary conditions. Eng Struct 2020;207:110198. 
[22] Furtado A, Costa C, Arêde A, Rodrigues H. Geometric characterisation of Portuguese RC buildings with masonry infill walls. Eur J Environ Civ Eng 2016: $1-16$.

[23] Furtado A. Seismic vulnerability assessment and retrofitting strategies for masonry infilled frame buildings considering in-plane and out-of-plane behaviour. $\mathrm{PhD}$

Thesis. Porto, Portugal: Faculdade de Engenharia da Universidade do Porto, Universidade do Porto; 2020.

[24] CEN. NP EN10002-1 - Tensile testing of mettalic materials - Part 1: Method of test t ambient temperature. European Committee for Standardization: 2006.

[25] CEN. EN 1052-1 Methods of test for masonry - Part 1: Determination of compressive strength; 1998.
[26] RILEM. RILEM TC 76-LUM. Diagonal tensile strength of small walls specimens. RILEM Publications SARL; 1994

[27] CEN. EN 1052-2: Methods of test for masonry. Determination of flexural strength; 1999.

[28] CEN. EN 196-2006 Methods of testing cement (European Committee for Standardization); 2006

[29] Furtado A, Rodrigues H, Arede A, Varum H. Experimental investigation on the possible effect of previous damage, workmanship and test setup on the out-of-plane behaviour of masonry infill walls. J Earthq Eng 2021:1-32. 